\title{
Two-beam interdigital-H-type radio frequency quadrupole linac with direct plasma injection for high intensity heavy ion acceleration
}

\author{
T. Ishibashi, ${ }^{1}$ N. Hayashizaki, ${ }^{2}$ and T. Hattori ${ }^{2}$ \\ ${ }^{1}$ KEK Accelerator Laboratory, Ibaraki, 305-0801, Japan \\ ${ }^{2}$ Research Laboratory for Nuclear Reactors, Tokyo Institute of Technology, Tokyo, 152-8550, Japan
}

(Received 30 November 2010; published 17 June 2011)

\begin{abstract}
We developed a two-beam interdigital-H-type radio frequency quadrupole (IH-RFQ) linac as a prototype of a multibeam IH-RFQ for high intensity heavy ion acceleration in the low energy region. This linac has two sets of RFQ electrodes within an IH-type resonant frequency cavity that is a powerefficient structure for low energy beam acceleration. The linac can accelerate two beams in parallel in one cavity with a reduction in the coulomb repulsive force (the space charge effect) between the accelerated heavy ion particles. The resonance frequency and the $Q$ factor of the linac were found to be $47 \mathrm{MHz}$ and 5900 , respectively. We also developed a two-beam laser ion source with a direct plasma injection scheme as an injection system for the two-beam IH-RFQ linac and built a system to demonstrate the use of the two-beam IH-RFQ linac. Using this linac system, we were able to accelerate carbon ions from 5 to $60 \mathrm{keV} / \mathrm{u}$ and generate an output beam current of about $108 \mathrm{~mA}(2 \times 54 \mathrm{~mA} /$ channel $)$. A coherency between the two beams, derived from the imbalance of the beam loading, was observed in the acceleration test with carbon ions.
\end{abstract}

DOI: 10.1103/PhysRevSTAB.14.060101

PACS numbers: 29.20.Ej, 41.75.Ak, 29.25.Ni, 52.59.Sa

\section{INTRODUCTION}

Radio frequency quadrupole (RFQ) linacs accelerate beams with strong focusing. It is possible to achieve greater than $90 \%$ transmission rates of accelerated particles, the ratio of the number of injected particles to the number of output particles. An accelerator system using the RFQ linac does not need an electrostatic accelerator at the particle injection stage. The linac can be used for standalone low energy beam acceleration. The RFQ linac accelerates direct current (DC) beams with bunching, so the injection system of the RFQ linac does not need bunchers. RFQ linacs are often used as a first stage linac for a highenergy accelerator complex. RFQ linacs of varied types have been studied and developed in the past. A four-vane RFQ linac for proton or light ion acceleration and a fourrod RFQ linac for heavy ion acceleration are in widespread use because of the simple design and ease of manufacture.

One reason it is difficult to generate a high intensity heavy ion beam from the RFQ linac is the coulomb repulsive force (space charge effect) between the accelerated particles. The upper limit of the beam current depends on the applied voltage at the RFQ electrode and the strength of the space charge effect. The beam current limit is proportional to $\beta V^{2}$ in the transverse direction and proportional to $V$ in the longitudinal direction, where $\beta$ is the ratio of the beam velocity to the velocity of light, and $V$ is the

Published by the American Physical Society under the terms of the Creative Commons Attribution 3.0 License. Further distribution of this work must maintain attribution to the author(s) and the published article's title, journal citation, and DOI. applied voltage at the RFQ electrode [1]. The electric discharge limits the applied maximum voltage, so it is difficult to generate heavy ions, large in mass and a low $\beta$, with high intensity.

A $60 \mathrm{~mA}$ carbon beam current was generated using a laser ion source with direct plasma injection scheme (DPIS) as the injection system [2]. This has been holding the world record as the highest heavy ion beam current generated by a single RFQ linac. In order to achieve a higher beam current, such as $100 \mathrm{~mA}$ or more, one would need a set of several in parallel-operated linacs. Using this acceleration method, the number of peripheral devices, such as the evacuation systems, the ion sources, the $\mathrm{rf}$ amplifiers, the control systems, and so on, increase depending on the required output beam. There is therefore an issue associated with the size of the acceleration system, the cost of construction, and the cost of operation.

We have studied a multibeam RFQ linac system, with multiple channels accelerating several beams in parallel in one cavity, in order to generate high intensity heavy ion beams without a significant increase in the size of the linac system. For instance, a single acceleration cavity can be used to accelerate four beams in parallel in a four-beam RFQ system. The four-beam system has almost the same performance in beam acceleration and transportation as a set of four individual conventional linac systems.

However, structures of the ion sources and the low energy beam transport (LEBT), a beam transport system consisting of focusing elements between the ion source and the RFQ linac, increase in complexity as the number of acceleration beams is increased. As a solution to this problem, we have adopted and developed a laser ion source 
with DPIS as the injection system of a multibeam RFQ linac. In this scheme, the laser ion source is connected to the RFQ cavity directly without a LEBT.

In order to accelerate heavy ions in the low energy regime, it is necessary to lower the resonance frequency of the cavity to dozen $\mathrm{MHz}$ - the frequency needs to be synchronized with the low beam velocity. We can replace the RFQ acceleration cavity with an equivalent LCR (inductance-capacitance-resistance) circuit; the RFQ electrodes are the capacitance, and the through-area magnetic flux is the inductance, where the resonance frequency is proportional to (LC) ${ }^{-0.5}$. A cavity diameter of the multibeam linac is more compact than that of the single beam linac to achieve a low resonance frequency because the multibeam cavity has a large capacitance compared to the single beam cavity. The multibeam RFQ linac could be developed with significant downsizing and cost savings.

A multibeam four-rod RFQ linac was proposed at Goethe University $[3,4]$. A two-beam linac as a prototype of the multibeam four-rod RFQ linac was developed, and beam transport experiments were performed. A single beam high current IH-RFQ was successfully developed and realized at GSI Darmstadt and is in routine operation since 1999 to accelerate up to $20 \mathrm{~mA} \mathrm{U}^{4+}$ beams from 2.2 to $120 \mathrm{keV} / \mathrm{u}$ [5]. A multibeam IH-RFQ linac, a powerefficient structure for low energy beam acceleration, was proposed in GSI [6], but not realized. We propose a fourrod or an interdigital-H (IH) cavity as the structure for a multibeam cavity. We have designed and developed a twobeam system as a prototype of the multibeam IH-RFQ linac and performed proof-of-principle beam acceleration tests. During these tests, we evaluated the advantages of the multibeam IH-RFQ linac quantitatively; coherency in each beam channel was observed in this test.

\section{DESIGN AND PARAMETERS OF THE RFQ LINAC}

\section{A. General considerations}

The basic parameters of the linac, the benchmarks for this study, are shown in Table I. The lower charge to mass ratio $(q / A)$ suits high intensity beam acceleration because the effect of the space charge effect is weaker. However, the linac cannot accelerate the particles to a sufficient velocity within the cavity length when the $q / A$ is extremely low. In this work, we selected $q / A=1 / 6$ because the acceleration cavity length was limited to $1-2 \mathrm{~m}$ due to limitations in the installation space and the construction costs.

We used an existing rf power source for the beam acceleration test. The preamplifier and the main amplifier of the rf power source have a triode (3CX10000U7) and a tetrode (4CW100000E), respectively. This source outputs $50 \pm 5 \mathrm{MHz}$ in frequency and $100 \mathrm{~kW}$ in maximum power during pulse operation. The resonance frequency of the linac was set to about $48 \mathrm{MHz}$ because the rf power source
TABLE I. Basic parameter set of the two-beam IH-RFQ linac.

\begin{tabular}{lc}
\hline \hline Charge to mass ratio $(q / A)$ & More than $1 / 6$ \\
Cavity length $(\mathrm{m})$ & $1.5-2$ \\
Operational frequency $(\mathrm{MHz})$ & 48 \\
Total power consumption $(\mathrm{kW})$ & 80 \\
Input energy $(\mathrm{keV} / \mathrm{u})$ & 5 \\
Output energy $(\mathrm{keV} / \mathrm{u})$ & 60 \\
Input current $(\mathrm{mA})$ & $120(2 \times 60 \mathrm{~mA} /$ channel $)$ \\
Transmission $(\%)$ & 60 \\
Output current $(\mathrm{mA})$ & $70(2 \times 35 \mathrm{~mA} /$ channel $)$ \\
Kilpatrick factor & 1.8 \\
\hline \hline
\end{tabular}

can output a higher power at a lower frequency. There was the possibility that a higher voltage than the design value could be applied to the RFQ electrode in order to cover the separatrix reduction of the linac during the beam acceleration test. The higher rf power must also be available at the acceleration cavity in order to achieve the design voltage at the RFQ electrode when the $Q$ value of the actual cavity is lower than the design value; flexibility in the output power of the rf source is necessary. Thus, the acceleration cavity was designed for a beam loading of $35 \mathrm{~kW}$, a wall loss $45 \mathrm{~kW}$, and a total power consumption of $80 \mathrm{~kW}$ for the beam acceleration test. The Kilpatrick factor, the ratio of the applied voltage to the Kilpatrick criterion [7], of the RFQ electrode was set to 1.8 .

The input energy was set to about $5 \mathrm{keV} / \mathrm{u}$ to avoid electric discharge and the necessity for a large booster in the injection system. The output current and the output energy from the linac are dependent on the intended purpose of the beam. These parameters were selected to perform a proof of principle of the multibeam IH-RFQ. The maximum output beam current from a single beam RFQ linac without DPIS was about $35 \mathrm{~mA}$ per cavity in the other work, so we aimed for an output current from the two-beam IH-RFQ linac of about $70 \mathrm{~mA}$ $(2 \times 35 \mathrm{~mA} /$ channel $)$ or more per cavity. The output energy was set to $60 \mathrm{keV} / \mathrm{u}$, taking the beam loading into consideration, which is about $31 \mathrm{~kW}$ in this condition.

A rf electric field deflector was employed in the beam funneling system, integrating several output beams from each beam channel of an accelerator. Hence, the phase difference of two output bunches between each beam channel in the two-beam IH-RFQ linac is $\pi$ to integrate the two-beam into a single beam using the funneling system.

\section{B. Basic structure of the cavity}

An external view of the two-beam IH-RFQ linac is shown in Fig. 1(a). In order to install and align the structurally complex electrodes in the cavity, the cavity is composed of a center frame and two semicylindrical cavities. The center frame and the semicylindrical cavities are made of stainless steel and are coated with copper 


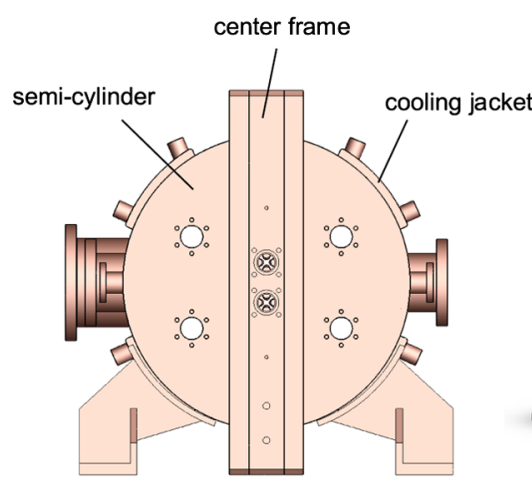

(a)

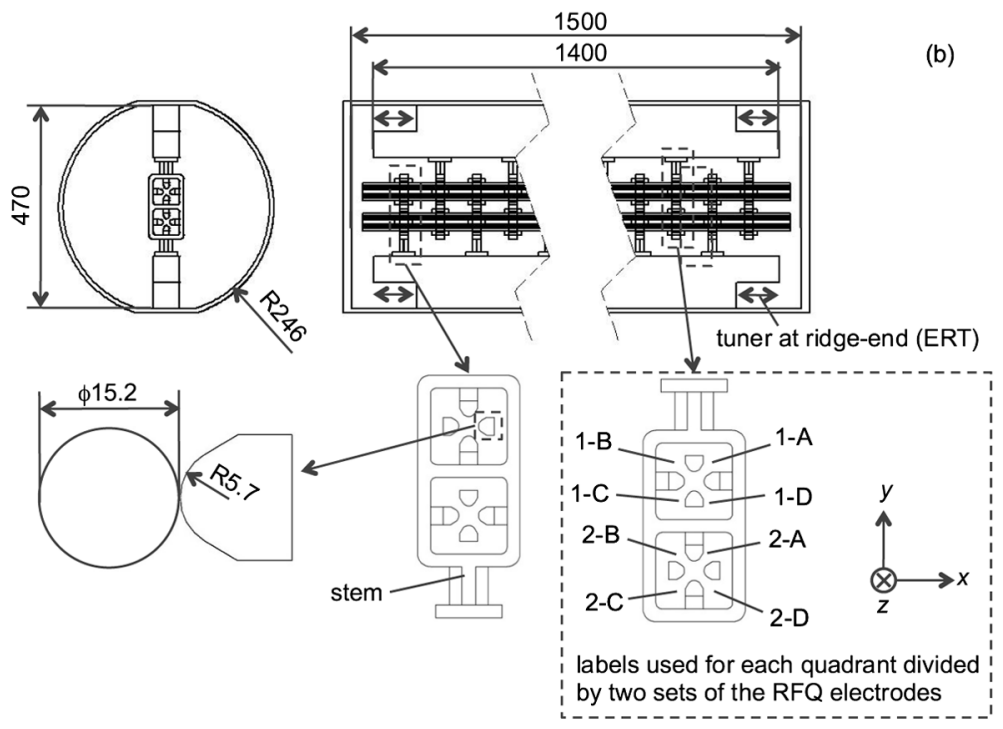

FIG. 1. Schematic diagram of the two-beam IH-RFQ cavity: (a) external view; (b) cross-section view.

approximately $50 \mu \mathrm{m}$ thick using electrolytic plating. The rf contacts are not used between the cavity and the electrodes. The rf electromagnetic field in the IH-type cavity is stimulated by the $\mathrm{TE}_{111}$ mode. Ridges extending from the top and bottom of the center frame are made with cutouts at the ends. We can adjust the area passing through the magnetic flux in the cavity by changing the length of the cutouts. The inductance of the cavity increases when the cutout length is longer, and the resonance frequency is lower. Stems, supporting the RFQ electrodes, are installed taking the electric polarity into consideration. The RFQ electric field is generated along the four rods.

\section{Beam dynamics simulation}

Using a beam dynamics simulation, we found that accelerated particles are obtained for $q / A=1 / 6$ from 5 to $60 \mathrm{keV} / \mathrm{u}$. The output beam current should be about $40 \mathrm{~mA} /$ channel with an input beam current of about $60 \mathrm{~mA} /$ channel [8]. In this simulation, we used RFQUICK, suitable for the design of high intensity RFQ linacs, to determine the cell parameters of the RFQ electrode. We input these parameters to PERMTEQM for the beam dynamics simulation [9].

Results of the beam dynamics simulation, using an optimized cell parameter set for the two-beam IH-RFQ, are summarized in Table II. For these cell parameters, the output beam current increases as the input current is increased, where the output current saturates at about $55 \mathrm{~mA} /$ channel when the input current is more than $120 \mathrm{~mA} /$ channel. The output current can be further increased by up to $9 \%$ by raising the interrod voltage corresponding to a Kilpatrick factor of 1.8 by about $20 \%$.

TABLE II. Summary of the PARMTEQM simulation parameters for an optimized cell parameter.

\begin{tabular}{lccc}
\hline \hline Input current $(\mathrm{mA} /$ channel $)$ & 60 & 140 & 60 \\
Input energy $(\mathrm{keV} / \mathrm{u})$ & 5 & 5 & 5 \\
Number of particles & 10000 & 10000 & 10000 \\
Transmission $(\%)$ & 73.3 & 39.3 & 81.7 \\
Output current $(\mathrm{mA} /$ channel) & 44 & 55 & 49 \\
Output energy $(\mathrm{keV} / \mathrm{u})$ & 60 & 60 & 60 \\
Kilpatrick factor & 1.8 & 1.8 & 2.2 \\
\hline \hline
\end{tabular}




\section{D. rf simulation}

We simulated the three-dimensional rf electromagnetic field in the acceleration cavity using MICRO-WAVE STUDIO (MWS) of Computer Simulation Technology (CST) Inc. for the design. The beam dynamics simulation code assumes that the transverse electric field strength in the RFQ electrode is constant along the cavity's longitudinal direction. Therefore, it is necessary to optimize the cavity structure to achieve the desired electric field strength in the two-beam IH-RFQ acceleration cavity. We also estimate that the tuner at the ridge end influences the rf properties. The basic design specifications were determined with a wall loss limit of about $45 \mathrm{~kW}$ for the cavity, since we optimize the cavity structure to suit the basic parameter in Table I. Each quadrant, divided into two sets of the RFQ electrode, is labeled as shown in Fig. 1(b). These labels are used throughout this paper, unless otherwise specified. The $x, y$, and $z$ axes in Fig. 1(b) refer to the horizontal, vertical, and longitudinal directions, respectively.

A model for the rf electromagnetic simulation is shown in Fig. 1(b). The RFQ electrodes of this simulation have no modulation along the rods to reduce the computation time. As a result of the cell parameter optimization, the beam aperture and the rod tip radius are 15.2 and $5.7 \mathrm{~mm}$, respectively. The MWS simulations showed that the cut length of the ridge end, called ERT in Fig. 1(b), influences the rf properties in this cavity. Interrod transverse electric field strength along the longitudinal direction of the cavity from $E R T=0 \mathrm{~mm}$ to $300 \mathrm{~mm}$ is shown in Fig. 2. A number of 16 stems were used in the simulation. The shoulder section of the electric field strength in this figure

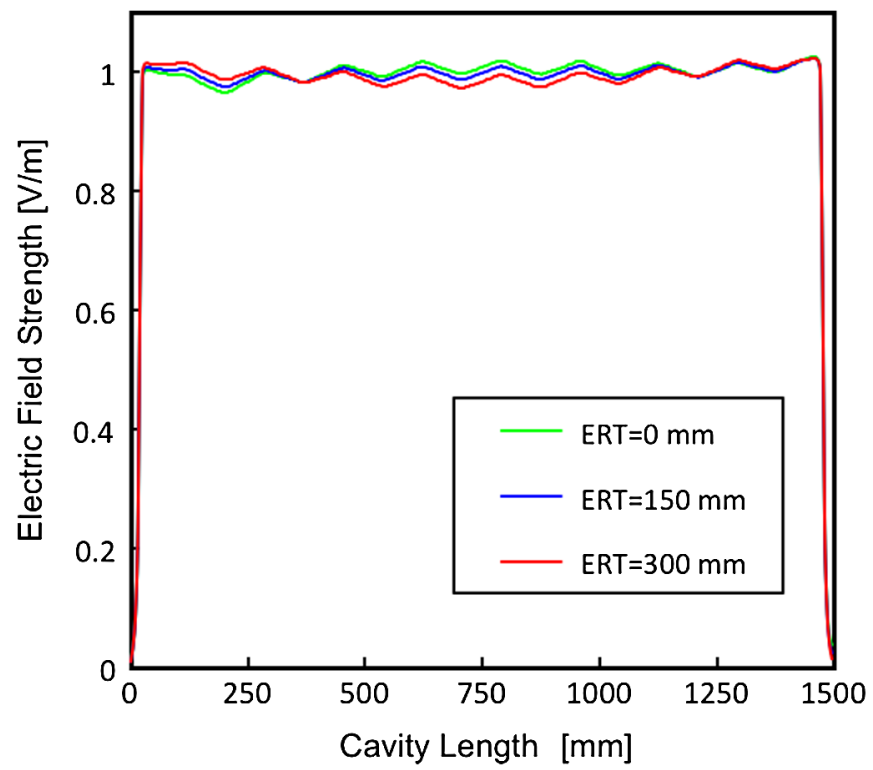

FIG. 2. Transverse electric field strength on 1-A for the $\mathrm{TE}_{111}$ mode. is off maximum $\pm 0.6 \%$ in $\mathrm{ERT}=0 \mathrm{~mm}$ and $\pm 0.4 \%$ in ERT $=300 \mathrm{~mm}$ with the average value of that strength. The ERT length affects less the distribution along the longitudinal direction of the electric field strength. As a result of this simulation, a constant electric field strength along the cavity is achieved in this structure for the dimensions shown in Fig. 1(b). The relationship between the ERT length variation and the resonance frequency shift $\Delta f$ is shown in Fig. 3. The resonance frequency shift in this cavity is about $19 \mathrm{kHz} / \mathrm{mm}$ for the ERT length.

The large capacitance at the electrode elements in this cavity results in a lower ERT effect on the distribution of the electric filed strength. In order to confirm this assumption, we designed a simple structure with only two ridges in the cavity as shown in Fig. 4. We simulated the rf electromagnetic field in this cavity for $\Delta=20 \mathrm{~mm}$ or $2 \mathrm{~mm}$, the gap length between the ridges. The distribution of the transverse electric field strength along the longitudinal direction of the cavity is shown in Fig. 5. Compared to the shoulder of the electric field strength plot, with

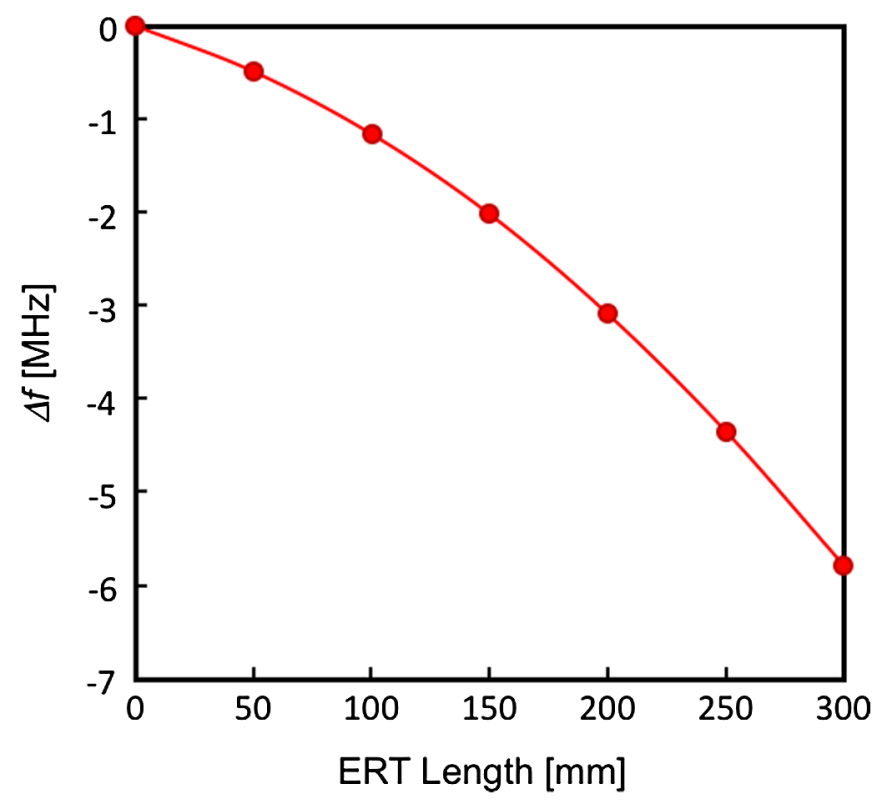

FIG. 3. Frequency shift as a function of the ERT length.

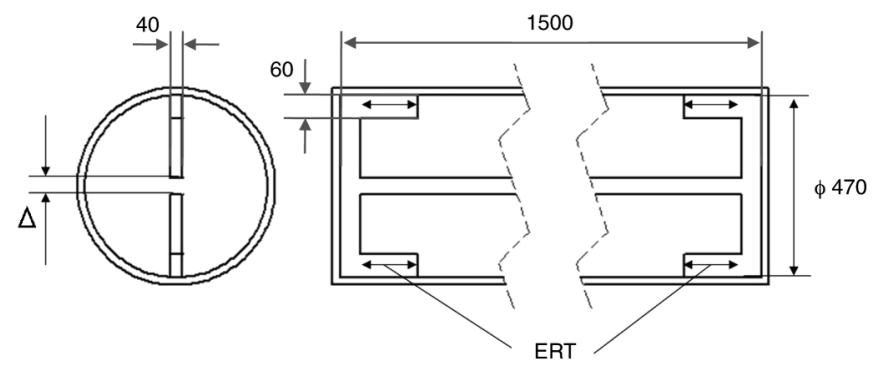

FIG. 4. A resonant cavity design with only two ridges (dimensions are in $\mathrm{mm}$ ). 

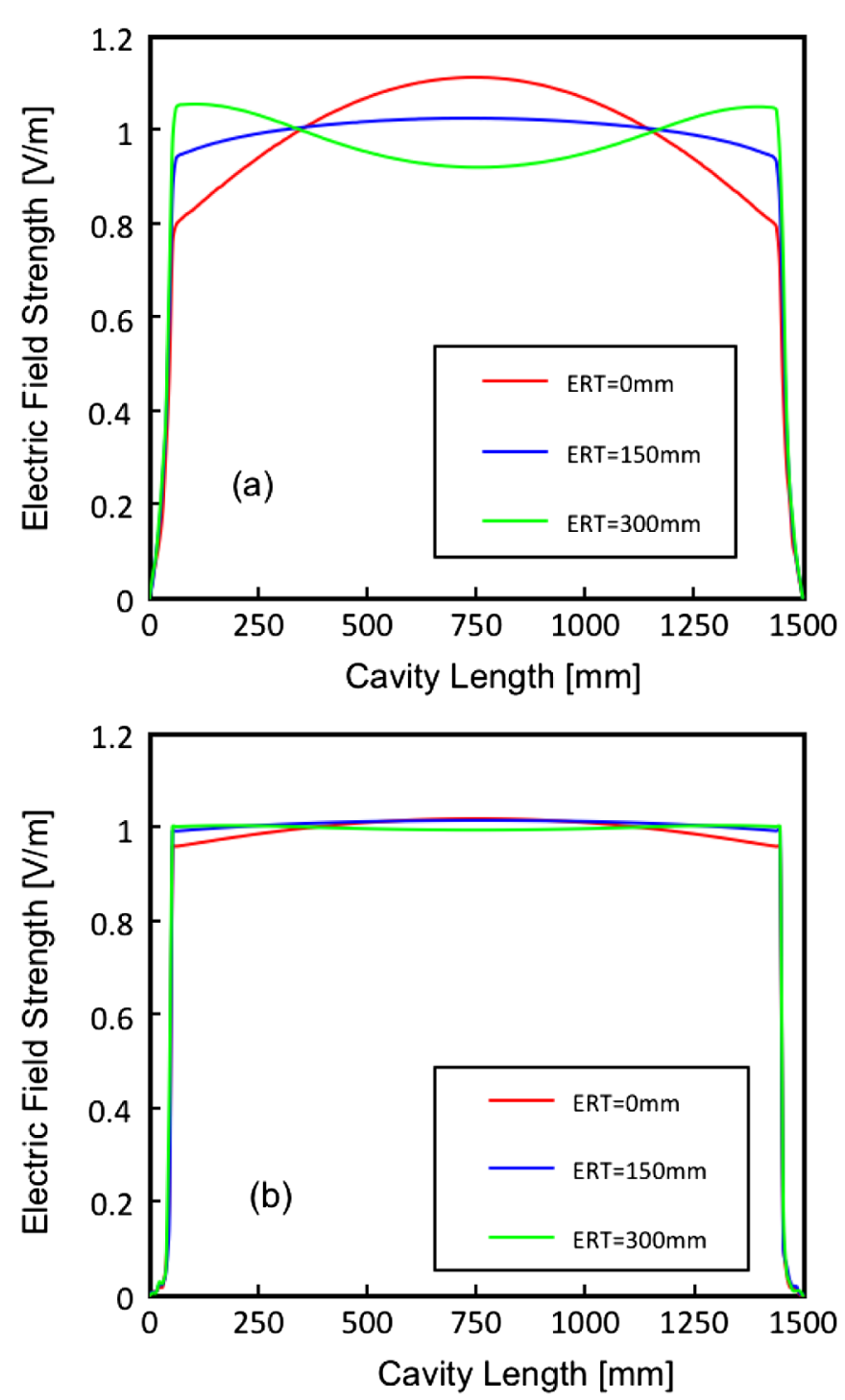

FIG. 5. Transverse electric field strength between ridges along the longitudinal direction of the cavity. Plots of electric field strength as a function of cavity length for (a) $\Delta=20 \mathrm{~mm}$ (gap length between the ridges) and (b) $\Delta=2 \mathrm{~mm}$ (gap length between the ridges).

ERT $=0 \mathrm{~mm}$ and $300 \mathrm{~mm}$, the strength change is about $24 \%$ for $\Delta=20 \mathrm{~mm}$ and about $4 \%$ for $\Delta=2 \mathrm{~mm}$. The ERT affects less the distribution with $\Delta=2 \mathrm{~mm}$, which exhibits a larger capacitance in the cavity, and the ERT affects less the distribution in the two-beam IH-RFQ linac because of the large capacitance of the cavity.

We estimated the wall loss for a linac length of 1.5 and $2 \mathrm{~m}$. In the simulations, the length between the stems in the cavity is $84 \mathrm{~mm}$. As a result, the power losses on the resistive wall for cavity designs with length of 1.5 and $2 \mathrm{~m}$ are 42 and $53 \mathrm{~kW}$, respectively. The output of the rf power source is not at an acceptable level for the cavity design with the length of $2 \mathrm{~m}$, so we adopted the cavity length of $1.5 \mathrm{~m}$.

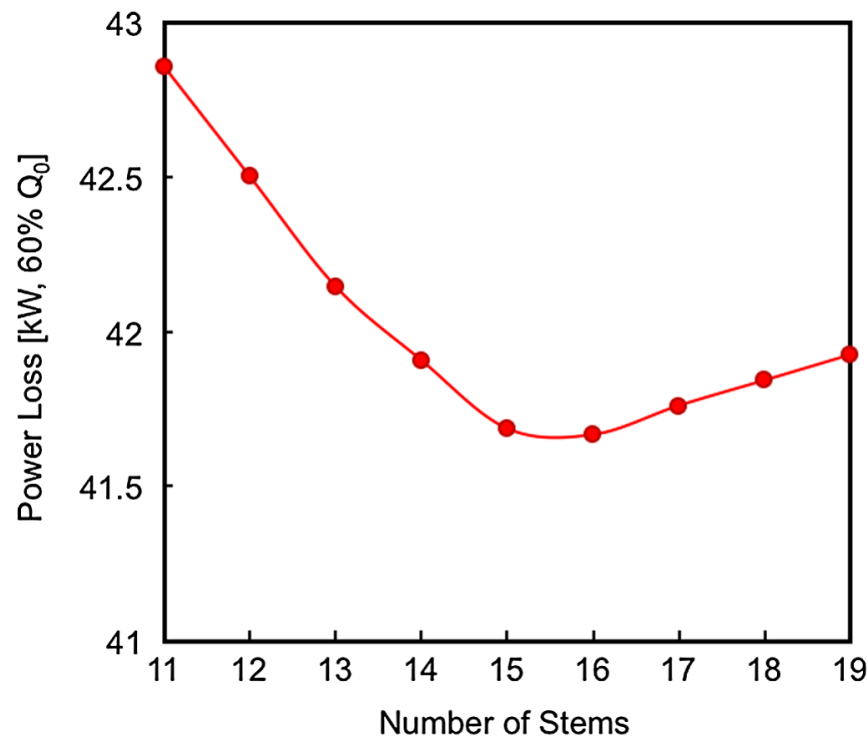

FIG. 6. A plot of the power loss as a function of the number of stems in the cavity. Wall loss is normalized with respect to the interrod voltage (Kilpatrick factor: 1.8).

The stems supporting the acceleration electrodes are current paths when in the rf power-on state; the consumed power decreases as the number of the stems is increased, directly related to the lower electric resistance. However, as the number of stems is increased above a given limit, the consumed power is found to also increase because the capacitance increases between nearby stems, and there is a minimum in the consumed power of the cavity with respect to the number of stems. The power loss as a function of the number of stems is shown in Fig. 6. We obtained an estimate of the wall loss from simulations [the linac model is illustrated in Fig. 1(b)] by changing the number of the stems without changing other features of the cavity structure. The simulations showed that the wall loss is about $41.7 \mathrm{~kW}$ (the minima of the data) for 16 stems; the actual linac was constructed using 16 stems in the cavity. The rod length and the distance between the ridges are 1466.41 and $230 \mathrm{~mm}$, respectively.

\section{E. Heat transfer and thermal stress simulation}

The linac acceleration cavity is subjected to stress due to heat induced in the cavity, attributed to joule heating on the inner walls of the cavity. The rf response of the cavity changes as the cavity is deformed, which can result in undesired effects during normal operation. A good estimate of this heating effect and the resulting stress over the cavity walls is necessary. Using a heattransfer analysis solver from COSMOS WORKS, we simulated heating in the cavity using actual beam acceleration parameters of Kilpatrick factor 1.8 and a duty of $1 \%$. The stems and the RFQ electrodes were set to copper, and the other components were set to stainless steel. We used 
TABLE III. Characteristic values of materials for heat-transfer and heat-stress simulations.

\begin{tabular}{lcccc}
\hline \hline Material & $\begin{array}{c}\text { Young's modulus } \\
\left(\mathrm{kgf} / \mathrm{mm}^{2}\right)\end{array}$ & Poisson's ratio & $\begin{array}{c}\text { Linear expansion } \\
\text { coefficient }\left(1 /{ }^{\circ} \mathrm{C}\right)\end{array}$ & $\begin{array}{c}\text { Thermal conductivity } \\
(\mathrm{W} / \mathrm{mK})\end{array}$ \\
\hline Stainless steel & 19700 & 0.3 & $1.55 \times 10^{-5}$ & 16 \\
Copper & 11900 & 0.368 & $1.70 \times 10^{-5}$ & 391 \\
\hline \hline
\end{tabular}

characteristic values of the materials as shown in Table III for the simulations.

The cooling structure of the center frame for the heattransfer simulation is shown in Fig. 7. The cross section of the stem is shown in Fig. 8. C1 and $\mathrm{C} 2$ refer to cooling circuits from stems labeled type A through eight rods in Fig. 7. The cooling water circulates around the inner stems labeled type B in C3-C14. C15-C18 refer to cooling circuits installed in the four corners of the center frame. The dimension of the cooling circuits is $4 \mathrm{~mm}$ in diameter, and we estimated the coefficient of heat transfer of the circuits at about $12142 \mathrm{~W} / \mathrm{m}^{2}$ with the water flow velocity of $2 \mathrm{~m} / \mathrm{s}$. Cooling jackets covering the outside of the semicylindrical cavities have rectangular water channels $1300 \times 200 \mathrm{~mm}$ in external dimensions and $15 \mathrm{~mm}$ in thickness. We estimated the coefficient of heat-transfer of the jacket at about $19401 \mathrm{~W} / \mathrm{m}^{2} \mathrm{~K}$ with the water flow velocity of $15 \mathrm{~m} / \mathrm{s}$. The thermal flux used input as the boundary condition for the heat-transfer simulation was determined using MWS, and the maximum thermal flux is $3030 \mathrm{~W} / \mathrm{m}^{2}$ at the stems. The results were used to calculate the stress distribution over the cavity walls. In order to estimate changes in the resonance frequency, with respects to the amount of deformation, we assumed that the displacement over the cavity walls is uniform and used these displacements to simulate the changes in the rf properties using MWS.

The temperature distribution and the displacement by the heat stress are shown in Figs. 9 and 10, respectively. The highest temperature is $30.9^{\circ} \mathrm{C}$ at the semicylindrical cavity, and the maximum displacement is $37 \mu \mathrm{m}$ at the ridge. In the displacement by the heat stress, the change in the resonance frequency is $3 \mathrm{kHz}$, and this is an acceptable level taking variability of the output frequency in the $\mathrm{rf}$

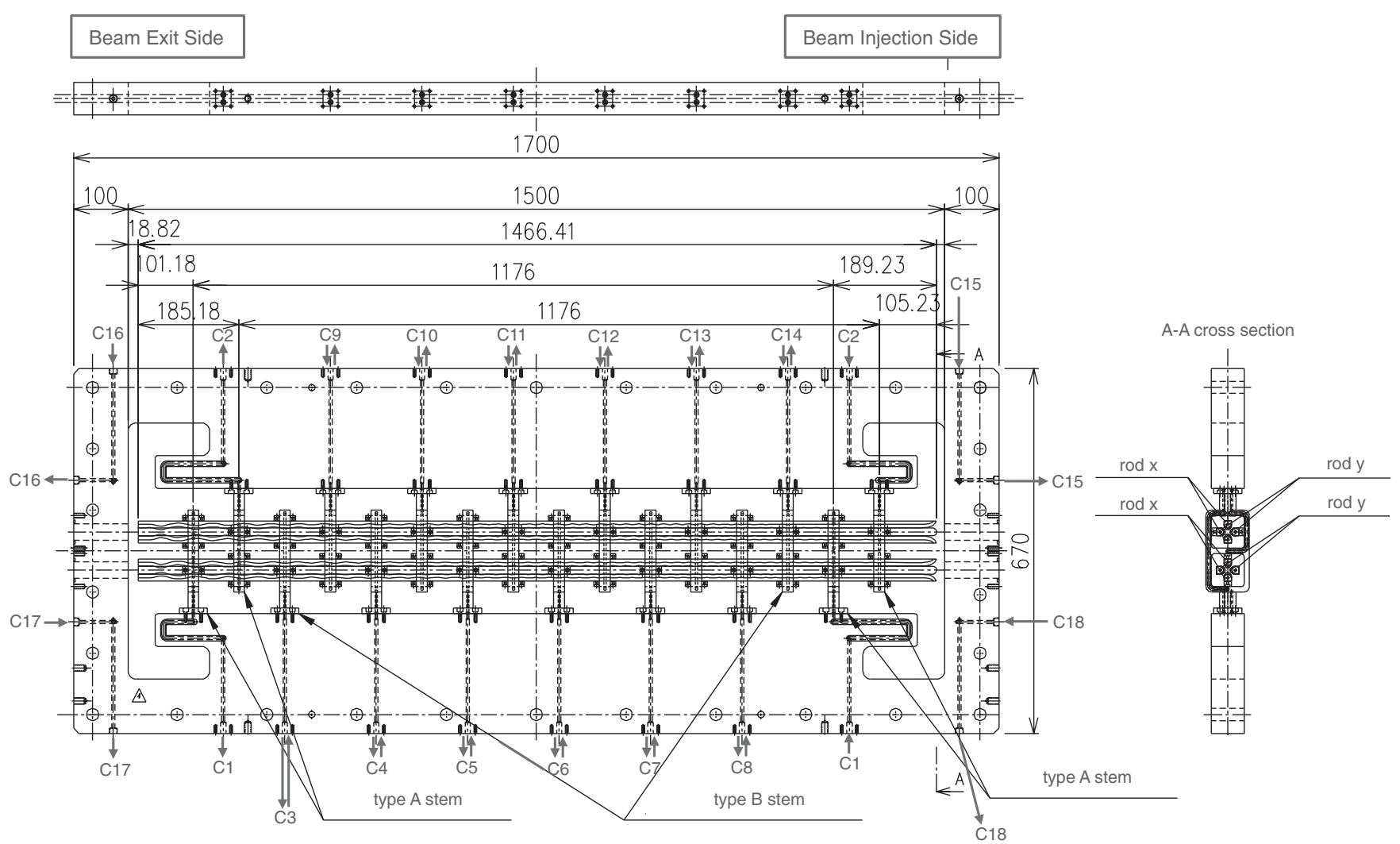

FIG. 7. Cooling structures in the heat-transfer and heat-stress simulations (dimensions are in mm). Dashed lines labeled C refer to circuits of cooling water. 

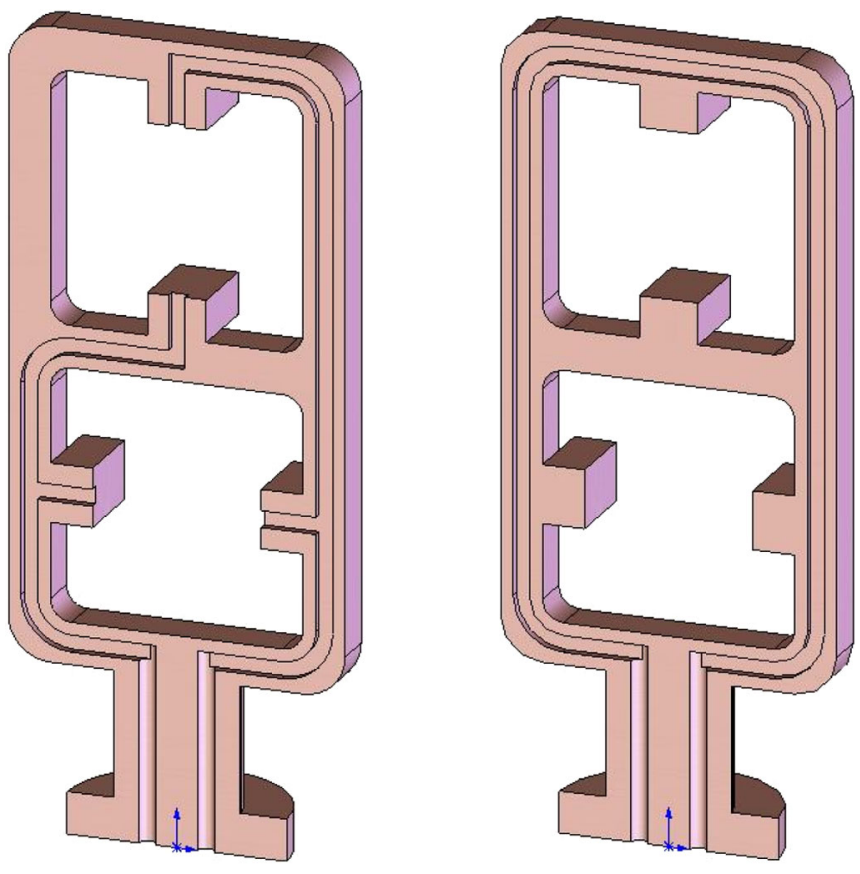

FIG. 8. Cross-section images of the stems.

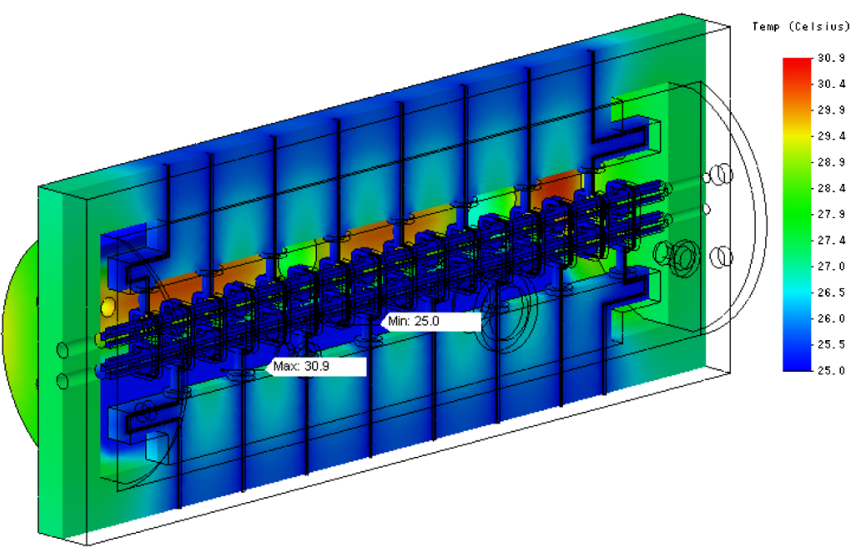

FIG. 9. Temperature distribution in the heat-transfer simulation. The room temperature is $25^{\circ} \mathrm{C}$.

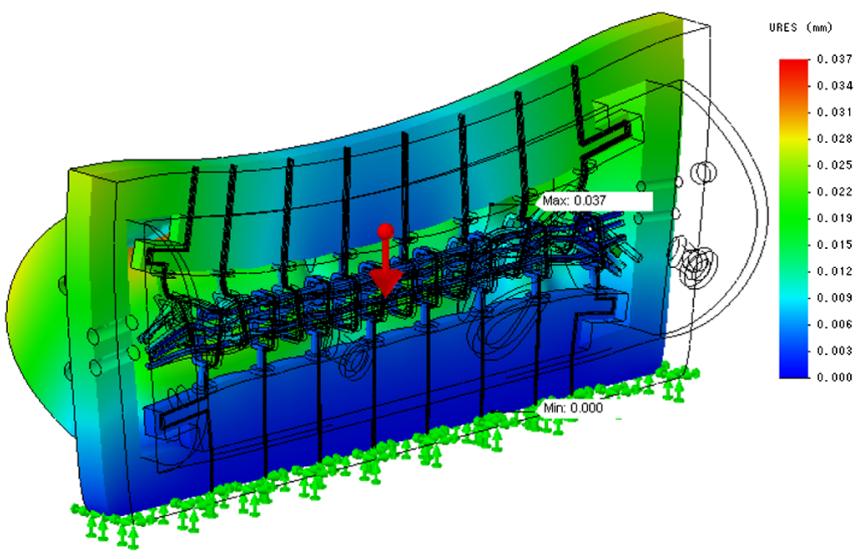

FIG. 10. Displacement of the linac by the heat stress. The room temperature is $25^{\circ} \mathrm{C}$. power source into consideration. The maximum rod displacement is $18 \mu \mathrm{m}$ at the rod end, and this is also an acceptable level taking a simulated acceptable error as we discuss next into consideration, so the cooling circuits are found to provide the desired level of heat transfer for safe and controlled operation.

\section{F. Acceptable error for manufacturing}

The machining error and the alignment error of the cavity and the electrode elements affect the performance of the linac directly. We simulate the effect of these errors on the resonance frequency, the electric field strength, and the beam dynamics and estimate the acceptable error for building the linac prototype.

The changes in the resonance frequency due to machining and alignment errors in the RFQ electrodes and the cavity were estimated using MWS. Possible changes due to these errors and the frequency changes are summarized in Table IV. Specifically, the displacement change in Table IV is in the direction that results in an increase in the resonance frequency. In the case of the maximum error in a dimension due to both a machining and alignment error, the maximum change in the resonance frequency is about $\pm 0.5 \mathrm{MHz}$ from the design value. The output from the $\mathrm{rf}$

TABLE IV. Changes in the resonance frequency with respect to changes in the dimensions in the two-beam IH-RFQ linac.

\begin{tabular}{|c|c|}
\hline Component with error & $\begin{array}{l}\text { Changes in the } \\
\text { resonance } \\
\text { frequency }(\mathrm{MHz})\end{array}$ \\
\hline Curvature radius of a rod tip & $0.157 / 50 \mu \mathrm{m}$ \\
\hline $\begin{array}{l}\text { Alignment to transverse direction } \\
\text { of a rod }\end{array}$ & $0.265 / 50 \mu \mathrm{m}$ \\
\hline Width of a rod & $0.001 / 50 \mu \mathrm{m}$ \\
\hline Width of a stem's frame & $0.000 / 100 \mu \mathrm{m}$ \\
\hline Bottom part of a stem's frame & $0.006 / 100 \mu \mathrm{m}$ \\
\hline Radius of a stem's axis & $0.022 / 100 \mu \mathrm{m}$ \\
\hline Height of a stem's pedestal & $0.000 / 100 \mu \mathrm{m}$ \\
\hline Radius of a stem's pedestal & $0.001 / 100 \mu \mathrm{m}$ \\
\hline Height of a ridge & $0.004 / 100 \mu \mathrm{m}$ \\
\hline Width of a ridge & $0.000 / 100 \mu \mathrm{m}$ \\
\hline Radius of a semicylindrical cavity & $0.018 / 100 \mu \mathrm{m}$ \\
\hline Inner dimension of a center frame & $0.019 / 100 \mu \mathrm{m}$ \\
\hline Length of a rod & $0.000 / 100 \mu \mathrm{m}$ \\
\hline $\begin{array}{l}\text { Alignment to longitudinal direction } \\
\text { of a rod }\end{array}$ & $0.002 / 100 \mu \mathrm{m}$ \\
\hline Length of a fixed part of a rod on a stem & $0.000 / 100 \mu \mathrm{m}$ \\
\hline Thickness of a stem's frame & $0.007 / 100 \mu \mathrm{m}$ \\
\hline Length of a ridge & $0.001 / 100 \mu \mathrm{m}$ \\
\hline Height of an ERT & $0.000 / 100 \mu \mathrm{m}$ \\
\hline Length of an ERT & $0.006 / 100 \mu \mathrm{m}$ \\
\hline Cavity length & $0.005 / 100 \mu \mathrm{m}$ \\
\hline Total & 0.512 \\
\hline
\end{tabular}




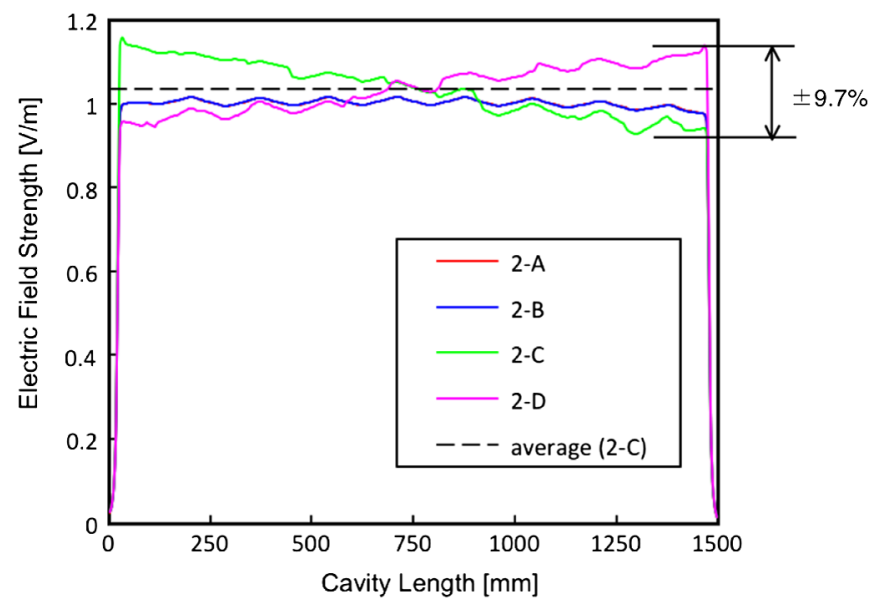

FIG. 11. A plot of the electric field strength as a function of the cavity length for different alignment errors that are normalized with respect to the average value of $2-\mathrm{C}$.

power source for the beam acceleration test is changeable to within $50 \pm 5 \mathrm{MHz}$, since we can assure these errors sufficiently by adjusting the rf power source. An acceptable alignment error of the rod for the required electric field strength is $\pm 500 \mu \mathrm{m}$, as described next. If the alignment errors of these RFQ electrodes fall inside this range, we can neglect this error since the change in the resonance frequency is only about $\pm 0.01 \mathrm{MHz}$.

An estimate of the electric field strength was obtained for a certain misalignment is a rod. A distribution of the transverse electric field strength along the cavity is shown in Fig. 11 when a rod between 2-C and 2-D in Fig. 1(b) is tilted a further $1 \mathrm{~mm}$ in the $x$ direction at the entrance of the RFQ electrode and $1 \mathrm{~mm}$ in the $x$ direction at the exit of the

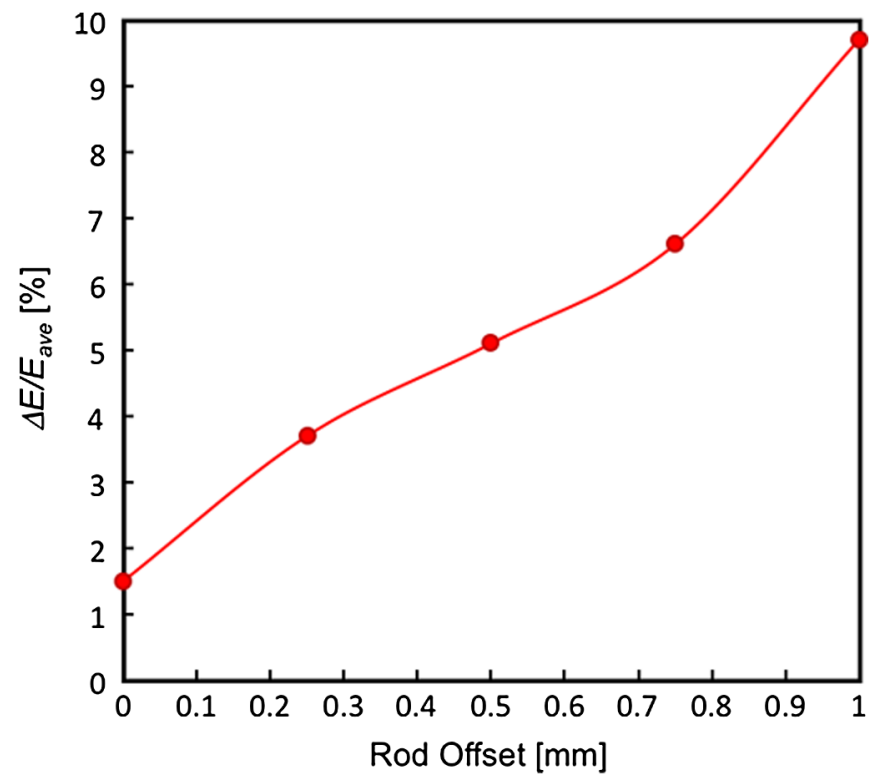

FIG. 12. The maximum change in the electric field strength along the cavity normalized with respect to the average field strength along the cavity.

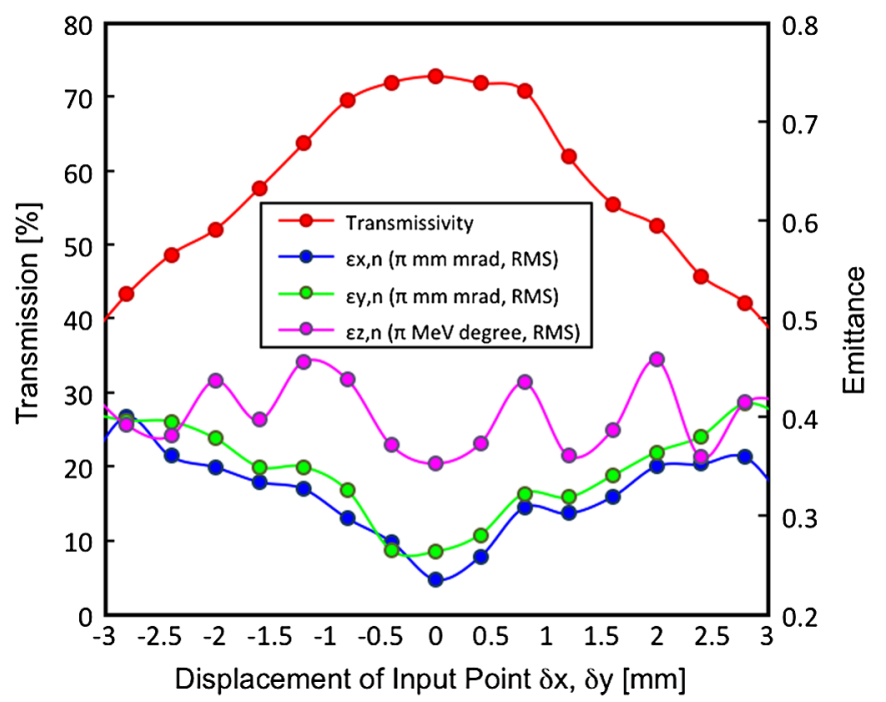

FIG. 13. Transmission and output emittance as a function of position error of input beam to the linac.

RFQ electrode. The rod is not tilted in the $y$ direction in this case. The electric field is strong at the entrance side of 2-C and the exit of 2-D because the distance between the two rods is shorter. The distribution of the electric field strength along the longitudinal direction of the cavity was found to be nonuniform. There is a maximum change from the average taken along the rod length of about $\pm 9.7 \%$ in the distribution on the 2-C and 2-D position.

The maximum change in the field strength, normalized with respect to the average field strength, is shown in Fig. 12. The vertical axis in the plot refers to $\Delta E / E_{\text {ave }}=$ $100 \times\left(E_{\max }-E_{\text {ave }}\right) / E_{\text {ave }}$, where $E_{\max }$ is a maximum value of the transverse electric field strength along the rod, and $E_{\text {ave }}$ is an average value of the transverse electric field strength along the rod. Over the length of the cavity, a

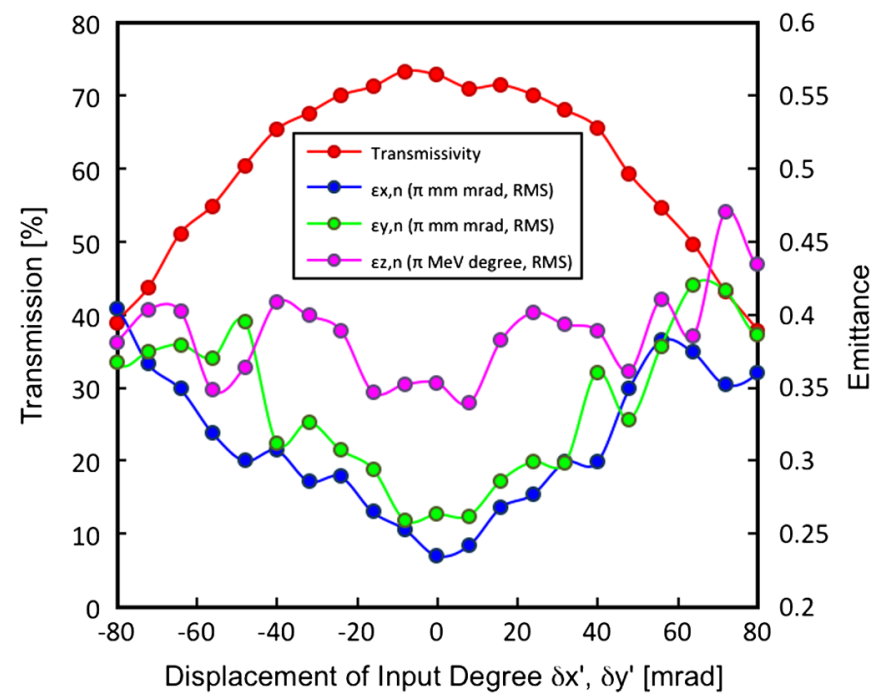

FIG. 14. Transmission and output emittance as a function of angle error of input beam to the linac. 
single rod is misaligned by approximately $\pm 100 \mu \mathrm{m}$ to the beam acceleration axis. Subsequently, this results in a change in the distribution of the electric field strength along the cavity of approximately $\pm 2.5 \%$ with respect to the average of the distribution. In previously manufactured RFQ linacs, the electric field error interrod are reduced to within $\pm 2.5 \%$. In the current design, the rod alignment error within $\pm 100 \mu \mathrm{m}$ for the two-beam IH-RFQ linac is considered acceptable because this error does not affect the beam dynamics significantly. This result was confirmed using the numerical simulations as shown in Fig. 13.

It is important to estimate the magnitude of the affect on the beam dynamics due to errors in the rod alignment. For different input position errors and input angle errors, the

TABLE V. Parameters of the two-beam IH-RFQ linac.

\begin{tabular}{|c|c|}
\hline Input and output current (mA) & $\begin{aligned} & 120 \rightarrow 88 \\
(2 \times 60 \rightarrow & 2 \times 44 \mathrm{~mA} / \text { channel })\end{aligned}$ \\
\hline Input and output energy $(\mathrm{keV} / \mathrm{u})$ & $5 \rightarrow 60$ \\
\hline $\begin{array}{l}\text { Resonance frequency } \\
\quad(\mathrm{MHz}, \text { calculated by MWS })\end{array}$ & 46.2 \\
\hline$Q$ factor (calculated by MWS) & 7500 \\
\hline $\begin{array}{l}\text { Interrod voltage } \\
\text { (Kilpatrick factor) }\end{array}$ & $85.3 \mathrm{kV}(1.8)$ \\
\hline$R / Q(\Omega)$ & 19 \\
\hline $\begin{array}{l}\text { Wall loss }(\mathrm{kW}, 60 \% Q \\
\quad \text { normalized by interrod voltage) }\end{array}$ & 42 \\
\hline Beam loading (kW) & 34 \\
\hline Total power consumption $(\mathrm{kW})$ & 76 \\
\hline $\begin{array}{l}\text { Normalized acceptance } \\
\qquad(\pi \mathrm{mm} \mathrm{mrad}, \mathrm{rms})\end{array}$ & 1.21 \\
\hline Synchronous phase & $-90^{\circ} \rightarrow-30^{\circ}$ \\
\hline $\begin{array}{l}\text { Output energy from shaper } \\
\text { section }(\mathrm{keV})\end{array}$ & 69.96 \\
\hline $\begin{array}{l}\text { Output energy from gentle } \\
\text { buncher section }(\mathrm{keV})\end{array}$ & 654 \\
\hline Focusing strength, $B$ & 8.754 \\
\hline rf defocusing strength, $|\Delta|$ & 0.216 \\
\hline Shape of rod tip & $0.75 r_{0}$ \\
\hline Modulation type & standard \\
\hline Curvature radius of rod tip (mm) & 5.7 \\
\hline Rod length (mm) & 1481.2 \\
\hline Maximum modulation index & 2.46 \\
\hline $\begin{array}{l}\text { Minimum beam aperture } \\
\text { radius }(\mathrm{mm})\end{array}$ & 4.51 \\
\hline $\begin{array}{l}\text { Average aperture radius, } \\
\quad r_{0}(\mathrm{~mm})\end{array}$ & 7.6 \\
\hline $\begin{array}{l}\text { Radius of semicylindrical } \\
\text { cavity }(\mathrm{mm})\end{array}$ & 492 \\
\hline ERT length $(\mathrm{mm})$ & 100 \\
\hline Number of stems & 16 \\
\hline $\begin{array}{l}\text { Number of cells in radial } \\
\text { matching section }\end{array}$ & 4 \\
\hline Number of cells in shaper section & 41 \\
\hline Number of cells in gentle buncher & 56 \\
\hline $\begin{array}{l}\text { Number of cells in } \\
\text { accelerator section }\end{array}$ & 1 \\
\hline $\begin{array}{l}\text { Number of cells in fringe field } \\
\text { section }\end{array}$ & 2 \\
\hline Total number of cells & 104 \\
\hline
\end{tabular}

beam transmission and the emittance as a function of the displacement of the input point are shown in Figs. 13 and 14, respectively. In the beam dynamics simulation, the input position and the input angle of the beam shift the same amount in the $x$ and $y$ directions. The transmission is $70 \%$ or more when the beams from the ion source of the injection system shift to within $\pm 1 \mathrm{~mm}$ or $\pm 25 \mathrm{mrad}$.

The parameters of the two-beam IH-RFQ linac were determined from numerical simulations, and are summarized in Table V.

\section{PROPERTY COMPARISON WITH OTHER STRUCTURES}

\section{A. Acceleration property}

We consider a situation in simulations that a single beam IH-RFQ cavity accelerates a beam, where $q / A=1 / 6$ and the input current is $120 \mathrm{~mA}$, from 5 to $60 \mathrm{keV} / \mathrm{u}$. The input and output beam parameters for the single beam IH-RFQ in the PARMTEQM simulations are shown in Table VI and VII, respectively.

The results of the dynamic simulations of the single and two-beam IH-RFQ linac are shown in Table VIII. The rf properties of the cavities were estimated using MWS for a simulation model as shown in Fig. 17(c). A cross area in the beam bore of the single beam IH-RFQ is twice that of the two-beam type, and the beam aperture radius of the single beam type is $\sqrt{2}$ times that of the two-beam type in Fig. 17(c).

The number of electrode components in the single beam type cavity is smaller than that in the two-beam type cavity,

TABLE VI. Input beam parameters for a single beam RFQ linac in the PARMTEQM simulation.

\begin{tabular}{lc}
\hline \hline Number of particles & 10000 \\
Transverse distribution & 4-D waterbag \\
Longitudinal distribution & random within ellipse \\
$\alpha_{t}$ & 5.8 \\
$\beta_{t}(\mathrm{~mm} / \mathrm{mrad})$ & 0.225 \\
$\varepsilon_{t}(\pi \mathrm{mm} \mathrm{mrad}, \mathrm{rms}$, normalized $)$ & 0.1 \\
\hline
\end{tabular}

TABLE VII. Output beam parameters from a single beam RFQ linac obtained from the PARMTEQM simulation.

\begin{tabular}{lc}
\hline \hline$\alpha_{x}$ & 1.6 \\
$\beta_{x}(\mathrm{~mm} / \mathrm{mrad})$ & 0.144 \\
$\varepsilon_{x}(\pi \mathrm{mm}$ mrad, rms, normalized $)$ & 0.55 \\
$\alpha_{y}(\mathrm{~mm} / \mathrm{mrad})$ & -1.6 \\
$\beta_{y}(\pi \mathrm{mm} \mathrm{mrad}, \mathrm{rms}$, normalized $)$ & 0.121 \\
$\varepsilon_{y}(\pi$ & 0.46 \\
$\alpha_{z}$ & 0.63 \\
$\beta_{z}($ degree$/ \mathrm{MeV})$ & 948 \\
$\varepsilon_{z}(\pi \mathrm{MeV}$ degree, $\mathrm{rms}$, normalized $)$ & 0.59 \\
\hline \hline
\end{tabular}


TABLE VIII. Main parameters comparison with single and two-beam type IH-RFQ linac for $q / A=1 / 6$ acceleration.

\begin{tabular}{|c|c|c|}
\hline & Two-beam type & Single beam type \\
\hline Resonance frequency (MHz) & 47.8 & 48.3 \\
\hline Cavity diameter (mm) & 470 & 680 \\
\hline Rod length (mm) & 1481 & 1538.5 \\
\hline Average aperture radius (mm) & 7.6 & 10.7 \\
\hline$Q$ factor (calculated by MWS) & 7200 & 9300 \\
\hline Wall loss $(\mathrm{kW}, 60 \% Q$, normalized by interrod voltage) & 72 & 52 \\
\hline Beam loading $(\mathrm{kW})$ & 36.4 & 29 \\
\hline Input-output energy $(\mathrm{keV} / \mathrm{u})$ & $5 \rightarrow 60$ & $5 \rightarrow 60$ \\
\hline Kilpatrick factor & 1.8 & 3 \\
\hline Normalized input emittance $(\pi \mathrm{mm} \mathrm{mrad}, \mathrm{rms})$ & 0.1 & 0.1 \\
\hline Normalized output emittance ( $\pi \mathrm{mm} \mathrm{mrad}, \mathrm{rms})$ & 0.2 & 0.5 \\
\hline Total cell number & 132 & 108 \\
\hline Focusing strength, $B$ & 8.754 & 7.960 \\
\hline Synchronous phase & $-90^{\circ} \rightarrow-30^{\circ}$ & $-90^{\circ} \rightarrow-30^{\circ}$ \\
\hline Input current $(\mathrm{mA})$ & $120(2 \times 60 \mathrm{~mA} /$ channel $)$ & 120 \\
\hline Transmission $(\%)$ & 72.7 & 46.7 \\
\hline Output current (mA) & $87.2(2 \times 43.6 \mathrm{~mA} /$ channel $)$ & 56.0 \\
\hline
\end{tabular}

so the cavity diameter of the single beam type is bigger for a resonance frequency of $48 \mathrm{MHz}$. The beam spread due to the space charge effect is pronounced in the single beam type because the charge amount in a beam channel is higher. The Kilpatrick factor interrod has to be therefore about 3 in order to have a transmission of $50 \%$ or more. RFQUICK changes the cell parameter adiabatically to reduce beam losses due to a strong space charge effect, so the rod length of the single beam IH-RFQ linac is longer than that of the two-beam type. Nevertheless, the transmission and the output current are only $46.7 \%$ and $56 \mathrm{~mA}$, respectively, because of the strong space charge effect. The output beam emittance from the single beam type is about 2.5 times compared to the two-beam type because the average aperture radius is larger. The power consumption of the single

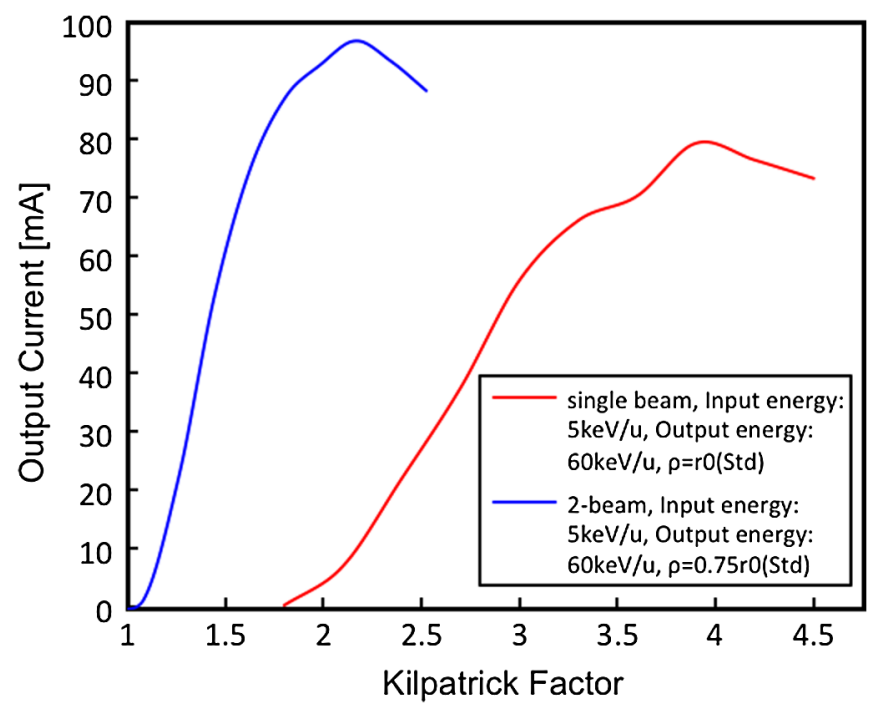

FIG. 15. Output current as a function of the Kilpatrick factor in a single and two-beam RFQ linac. Input current is $120 \mathrm{~mA}$. beam IH-RFQ linac is more efficient than that of the twobeam type because of the simple cavity structure. However, it is difficult to generate high intensity heavy ion beam acceleration in the low energy region, such as $100 \mathrm{~mA}$ or more in beam current and from a few $\mathrm{keV} / \mathrm{u}$ to dozens $\mathrm{keV} / \mathrm{u}$ in beam energy, from the standpoint of the limitation of the electric discharge in the RFQ electrodes and the beam transmission in the single beam IH-RFQ.

The output current as a function of the Kilpatrick factor is shown in Fig. 15. The output beam current of the single and the two-beam linac is saturated at about 80 and $96 \mathrm{~mA}$, respectively, along with the growing Kilpatrick factor. The

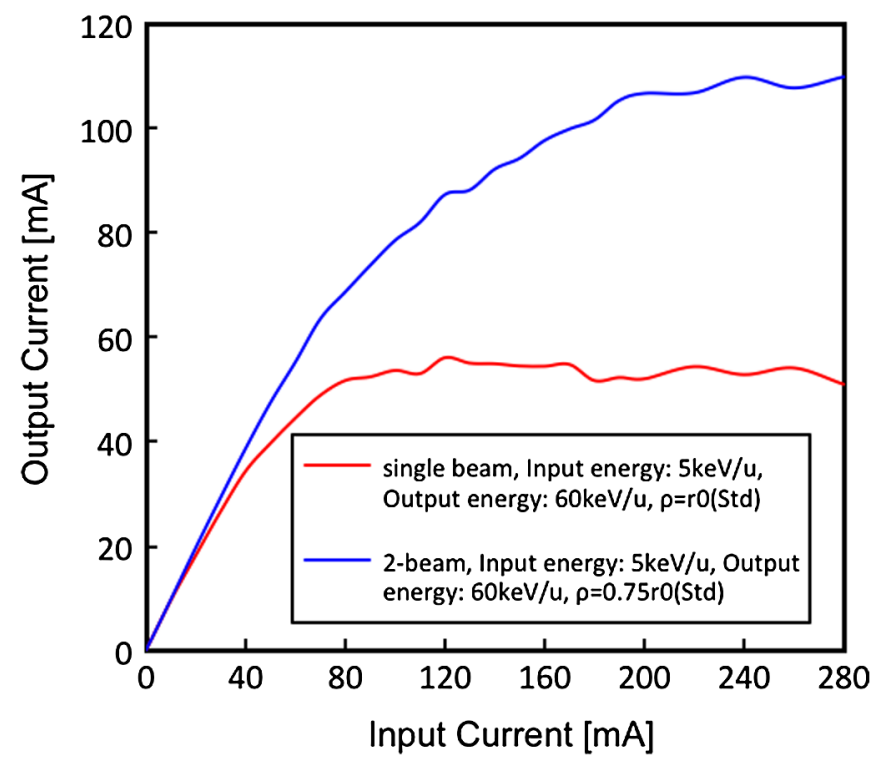

FIG. 16. Output current as a function of the input current in a single and two-beam RFQ linac. The Kilpatrick factors of the single and two-beam linac are 3 and 1.8, respectively. 

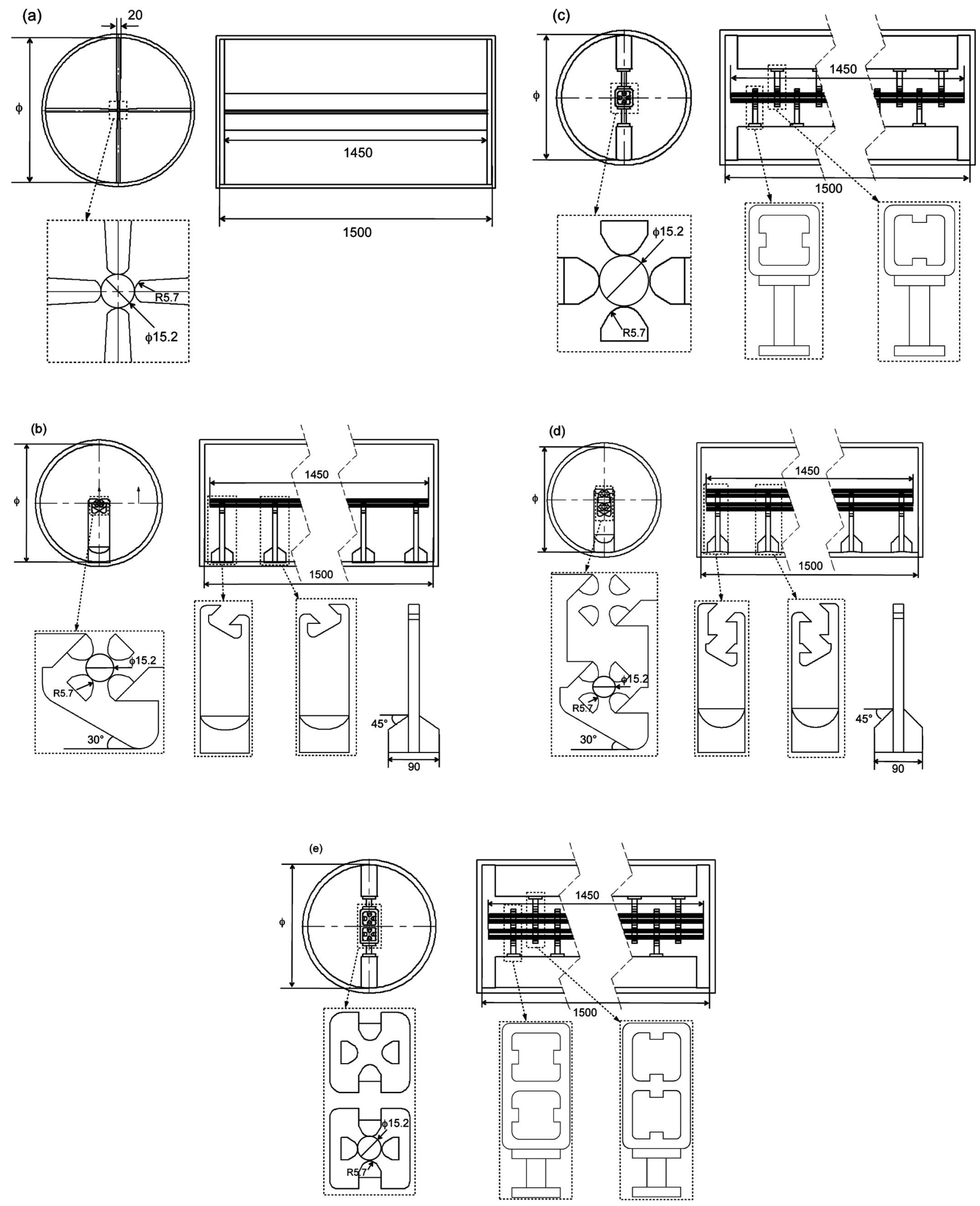

FIG. 17. Illustrations of the models of RFQ linacs for rf simulations using MWS (dimensions are in mm): (a) four vane, (b) four rod, (c) single beam type IH, (d) two-beam type four rod, and (e) two-beam type IH. 
output current as a function of the input current is shown in Fig. 16, when the interrod voltage is fixed. The difference in the output current from each cavity structure is about $10 \%$ until the input current is $20 \mathrm{~mA}$. The two-beam RFQ can output a double beam current when the input current is $200 \mathrm{~mA}$ or more. As a result, the transmission of the twobeam RFQ is much higher than that of the conventional methods used to accelerate heavy ion beams of $20 \mathrm{~mA}$ or more in the low energy region.

\section{B. rf property}

In this section, we consider the configuration where two single beam cavities accelerate two beams. We estimate the rf properties in each type cavity using MWS; the simulation models are shown in Fig. 17. We designed a simulation model of a four-rod RFQ cavity in Fig. 17(b) referring to the same structure by Frankfurt University [10], where also IH-RFQ and four-rod RFQ are compared to each other. Additionally, these two RFQ structures were compared to each other in previous research [11]. The beam bores, the shapes at the RFQ electrode tips, and the length of the cavities in each RFQ structure are the same as each simulation model of Fig. 17.

The resonance frequencies of each RFQ structure with the cavity diameter are shown in Fig. 18. The resonance frequency of the four-vane cavity, the simplest structure of all the simulation models, is higher than that of the other cavities. In order to achieve a low resonance frequency of a few dozen megahertz for heavy ion acceleration, the fourvane cavity must be several meters in diameter. In contrast, the downsizing of the diameter in the other cavities is limited by the structure of the electrodes, so it is difficult

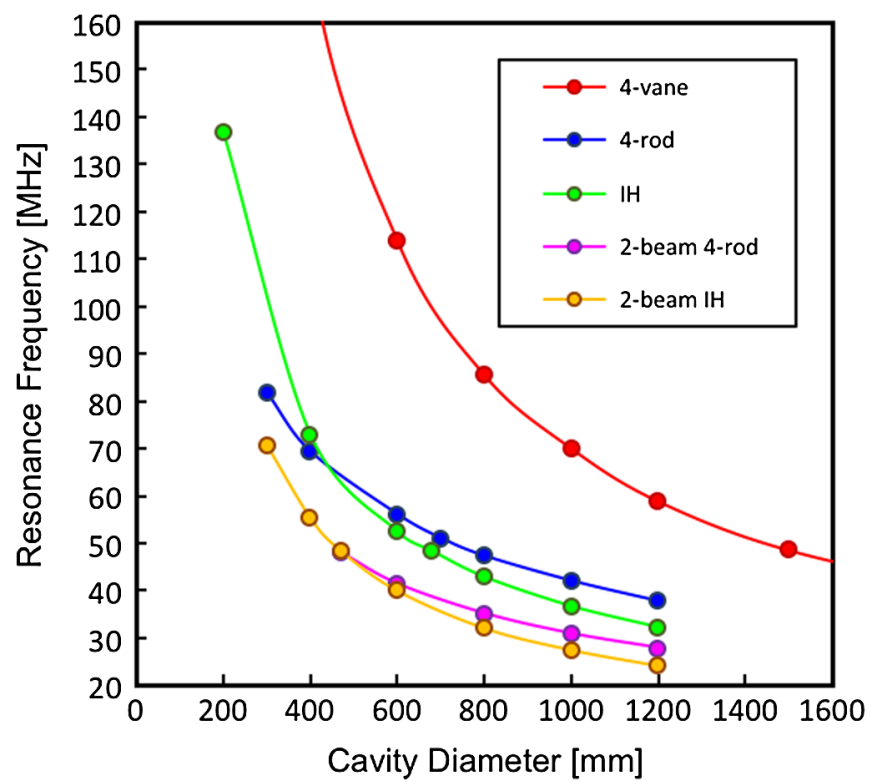

FIG. 18. Resonance frequency as a function of the cavity diameter of the RFQ linacs. The length of the cavities is $1.5 \mathrm{~m}$. to achieve high frequencies using these cavities. The fourvane cavity is suited to high frequency operation, which is several hundreds of megahertz for proton or light ion acceleration. The two-beam four-rod RFQ and the twobeam IH-RFQ achieve low resonance frequencies, which is several dozens of megahertz, with a smaller cavity diameter because these structures have a lot of electrode components and a high capacitance.

Shunt impedance of each structure with respect to the resonance frequency, proportional to the accelerated beam velocity, is shown in Fig. 19. The unit of shunt impedance in RFQ linacs is often represented as $\mathrm{k} \Omega \mathrm{m}$. The shunt impedance is inversely proportional to the power consumption per unit length in the cavity. As a result of the simulation, the shunt impedance of the four-vane cavity is higher than that of the other cavity at a frequency of about $75 \mathrm{MHz}$ or more. In the low frequency region, the shunt impedance of the single beam IH-RFQ structure is highest. Shunt impedances of the two-beam IH-RFQ and the two-beam four-rod RFQ are lower than the other cavities except for the four-vane type because the two cavities contain many electrodes. The shunt impedance in the two-beam IH-RFQ cavity is about half of that in the single beam IH-RFQ cavity. The shunt impedance in the two-beam four-rod RFQ cavity is about one-third of that in the single beam four-rod RFQ cavity. It is worth noting that one two-beam IH-RFQ cavity provides almost the same performance in power efficiency as two single beam IH-RFQ cavities. Adopting the two-beam IH-RFQ structure is therefore much better when considering the downsizing of the system and the construction cost of two-beam systems.

The rf properties of each RFQ cavity at a resonance frequency of about $48 \mathrm{MHz}$ are shown in Table IX. Clearly,

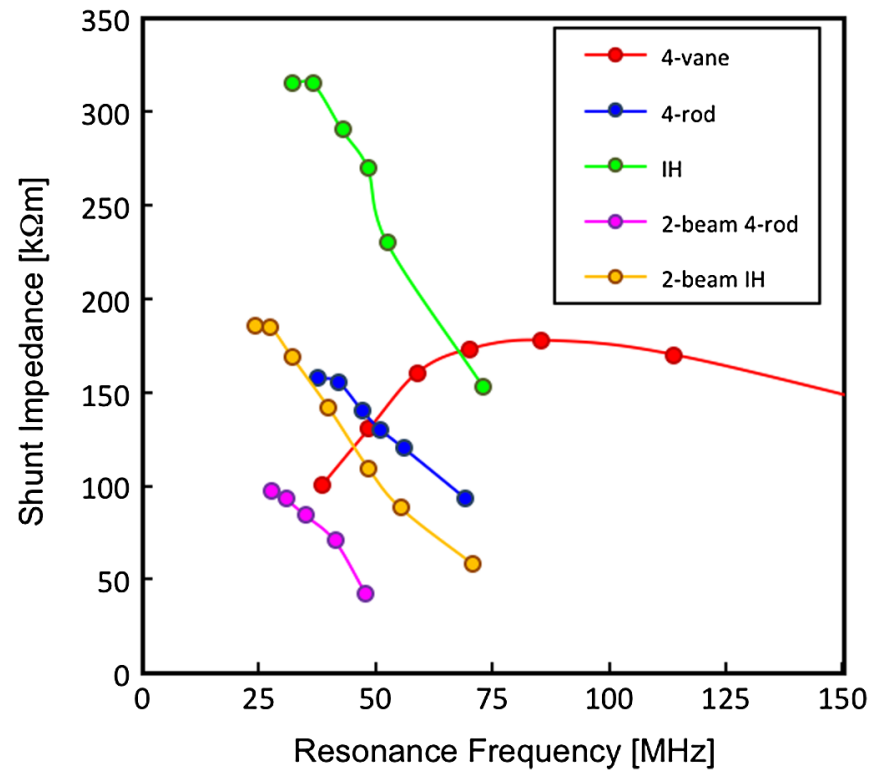

FIG. 19. Shunt impedance as a function of resonance frequency in the RFQ linacs. The shunt impedance is estimated as the Kilpatrick factor 1.8 and $60 \%$ calculated $Q$ factor. 
TABLE IX. The rf properties of the RFQ linacs at approximately the resonance frequency of $48 \mathrm{MHz}$.

\begin{tabular}{lccccc}
\hline \hline & Four vane & Four rod & IH & Two-beam type four rod & Two-beam type IH \\
\hline Resonance frequency (MHz) & 48.5 & 47.2 & 48.3 & 47.9 & 48.4 \\
Cavity diameter (mm) & 1500 & 800 & 680 & 470 & 470 \\
$Q$ factor & 6740 & 6580 & 9280 & 5310 & 7150 \\
Wall loss (kW/m, 60\% $Q$, & 33 & 33 & 16 & 100 & 34 \\
$\quad$ normalized by Kilpatrick factor 1.8) & & & & \\
\hline \hline
\end{tabular}

the cavity diameter of each of the single beam type structures needs to be larger, compared with each of the two-beam type structures, to achieve the resonance frequency of $48 \mathrm{MHz}$. The power efficiency of the single beam IH-RFQ cavity is higher than the other single beam cavities as previously described. However, when two single beam IH-RFQ cavities are used to accelerate two beams, the wall loss is $16 \mathrm{~kW} /$ cavity $\times 2$ cavities $=$ $32 \mathrm{~kW}$. The total wall loss in this situation is almost equal to the wall loss of $34 \mathrm{~kW}$ in one two-beam IH-RFQ cavity. The two-beam IH-RFQ is much more cost effective and simpler to operate because the vacuum systems, control regulation systems, rf power sources, and other components are needed for each cavity when using two single beam IH-RFQ cavities.

It is also possible to use one acceleration cavity to accelerate two beams. We designed a two-beam four-rod RFQ as shown in Fig. 17(d). The two-beam IH-RFQ and the twobeam four-rod RFQ can achieve a resonance frequency of $48 \mathrm{MHz}$ with approximately the same cavity diameter. The power efficiency of the two-beam IH-RFQ cavity is significantly better than that of the two-beam four-rod cavity.

\section{MANUFACTURING}

An image of the inside of the manufactured two-beam IH-RFQ is shown in Fig. 20. The stems supporting the RFQ electrodes were machined with the cooling circuits as shown in Fig. 7. A primitive form of the stem was made by means of joining and welding two copper blocks using electron beam, first machined with the cooling circuit. A numerical control (NC) machine was used to form the final shape of the stem.

A port for the vacuum system was installed on a semicylindrical cavity, and a grid of stainless steel coated with copper is welded to the port. This grid prevents current flow into the vacuum pump. An antenna, called a pickup, for monitoring the stored rf power in the cavity was also installed. An input coupler to inject the rf power is connected to the cavity with a magnetic coupling. The selfinductance of the coupler is about $86 \mathrm{nH}$, and impedance matching is possible by rotating the coupler about 60 degrees with respect to the vertical direction. It is assumed that the maximum output power and the maximum duty factor in the rf power source are $100 \mathrm{~kW}$ and $1 \%$, respectively, for the beam acceleration test, and a cooling of the coupler was not performed.
Using the data of the optimization of the cell parameters for the RFQ electrode, a three-dimensional computer aided design (CAD) file of the RFQ electrode geometry was produced. This file was then passed to an NC machine to produce the actual RFQ electrode. In order to make a rod with the cooling circuit, a gun drill machine was used to manufacture the cooling circuit of $4 \mathrm{~mm}$ inner diameter into five blocks of oxygen-free copper with a quadrangular prism. Using this method the machining error was negligible. Each rod was formed by means of welding the manufactured blocks using an electron beam. After
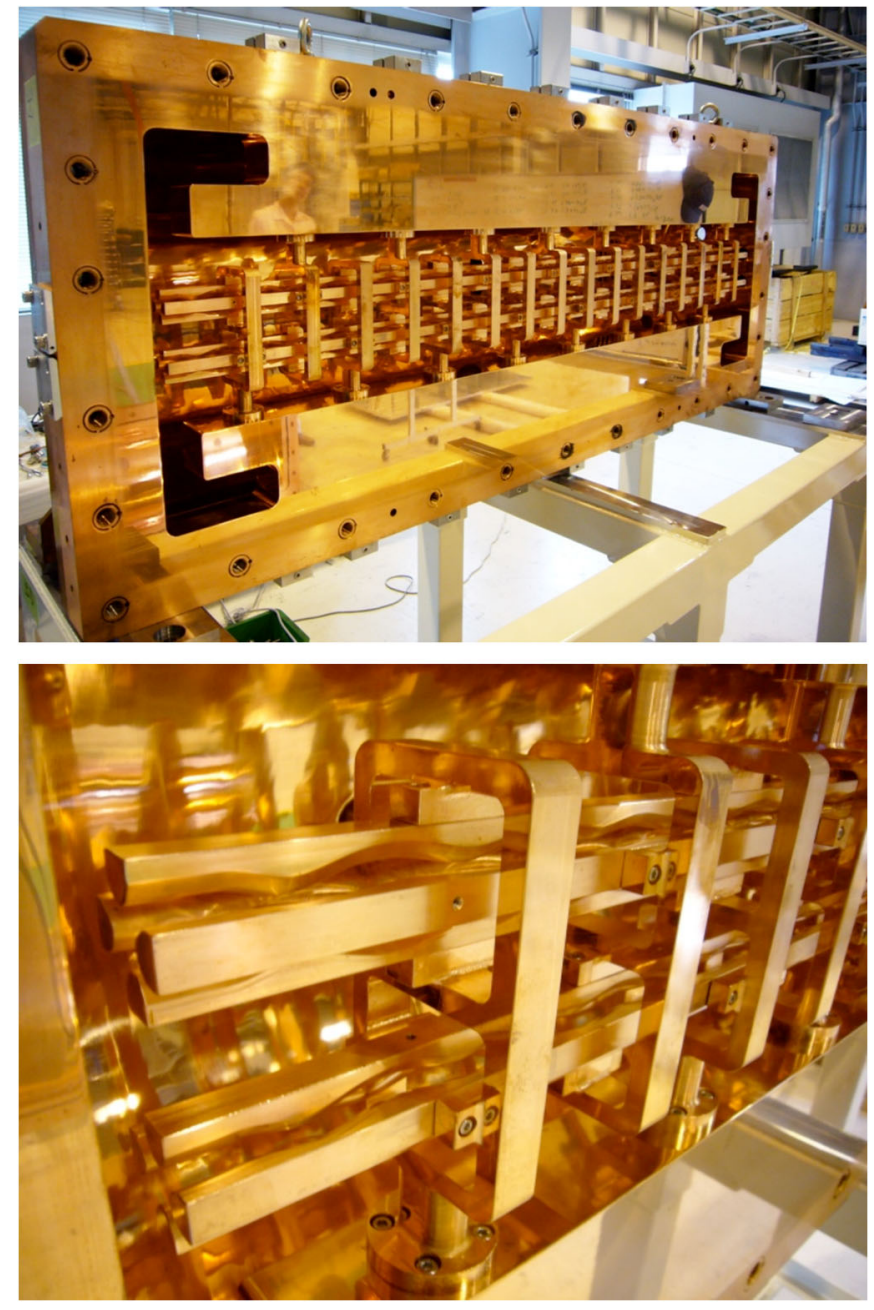

FIG. 20. A photo of the two-beam IH-RFQ linac. 


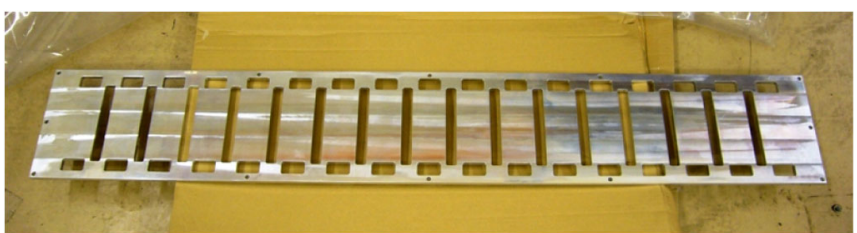

machining the tips of the rods, each rod was fixed on the stems using sixteen M3 bolts.

Jigs made of aluminum were manufactured to align the electrodes. In Fig. 21 the jig, $\pm 50 \mu \mathrm{m}$ in dimensional tolerance, was used to align the stems. The jig, $\pm 50 \mu \mathrm{m}$

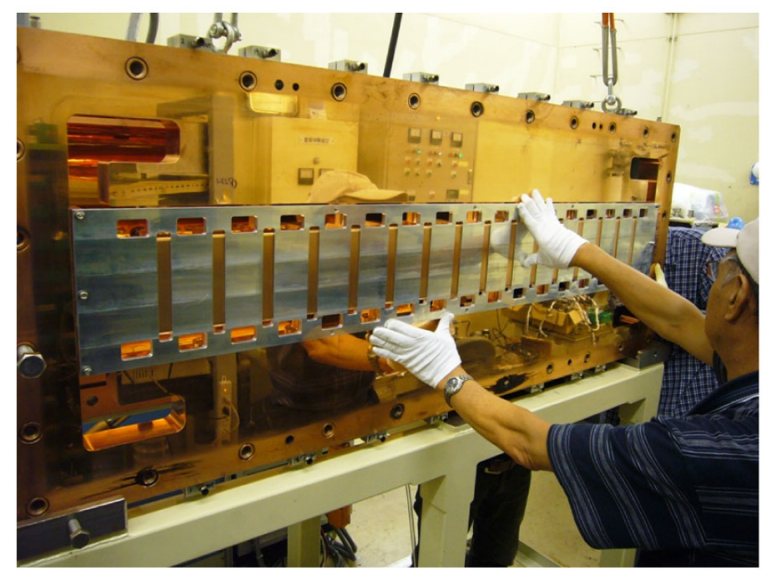
in dimensional tolerance, in Fig. 22 was used to align the rods, and a target, $\pm 20 \mu \mathrm{m}$ in dimensional tolerance, was used to align the RFQ electrode center position. Theodolite was used in the alignment of the center position.

\section{LOW POWER RF TESTS}

The main purpose of the low power rf tests was to measure the rf properties of the manufactured acceleration cavity; low power refers to several milliwatts. We used a

FIG. 21. Jig for stem installation.
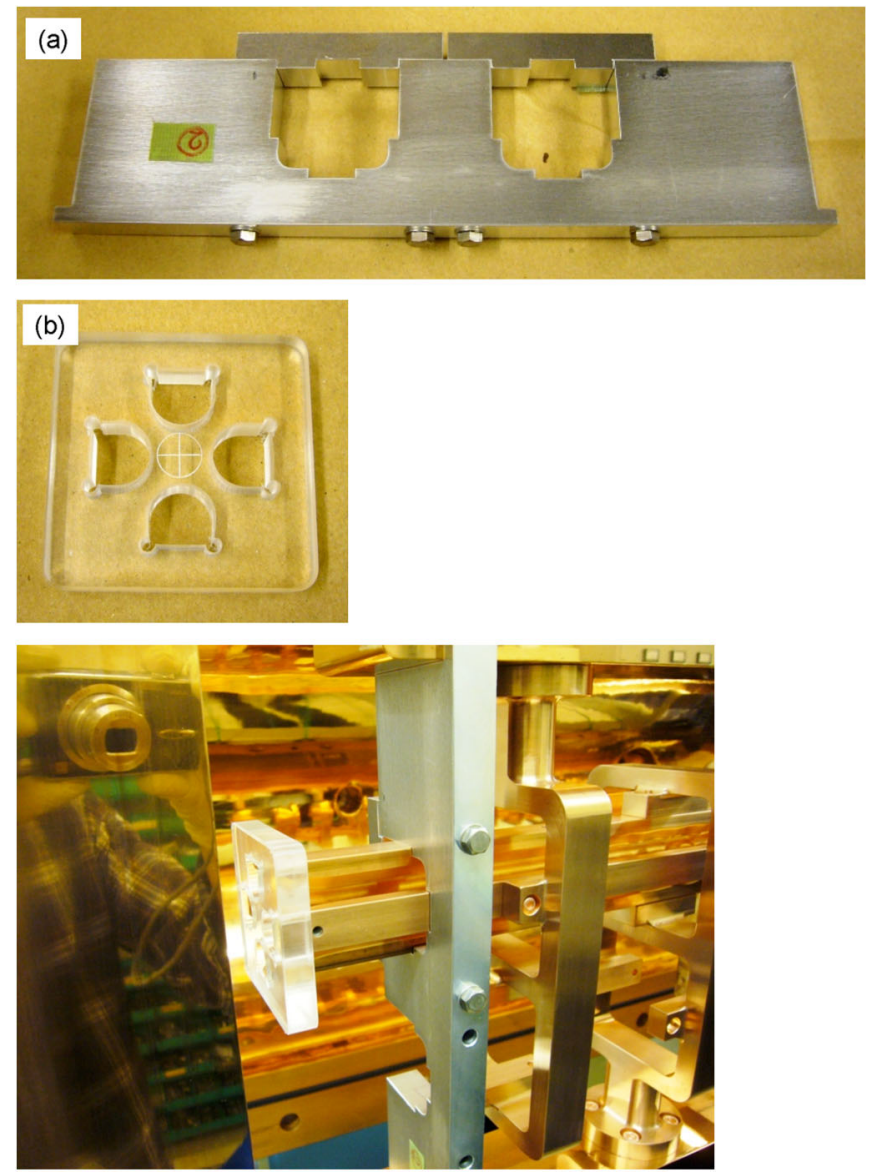

FIG. 22. (a) Jig for the rod installation and (b) target for the beam axis alignment.
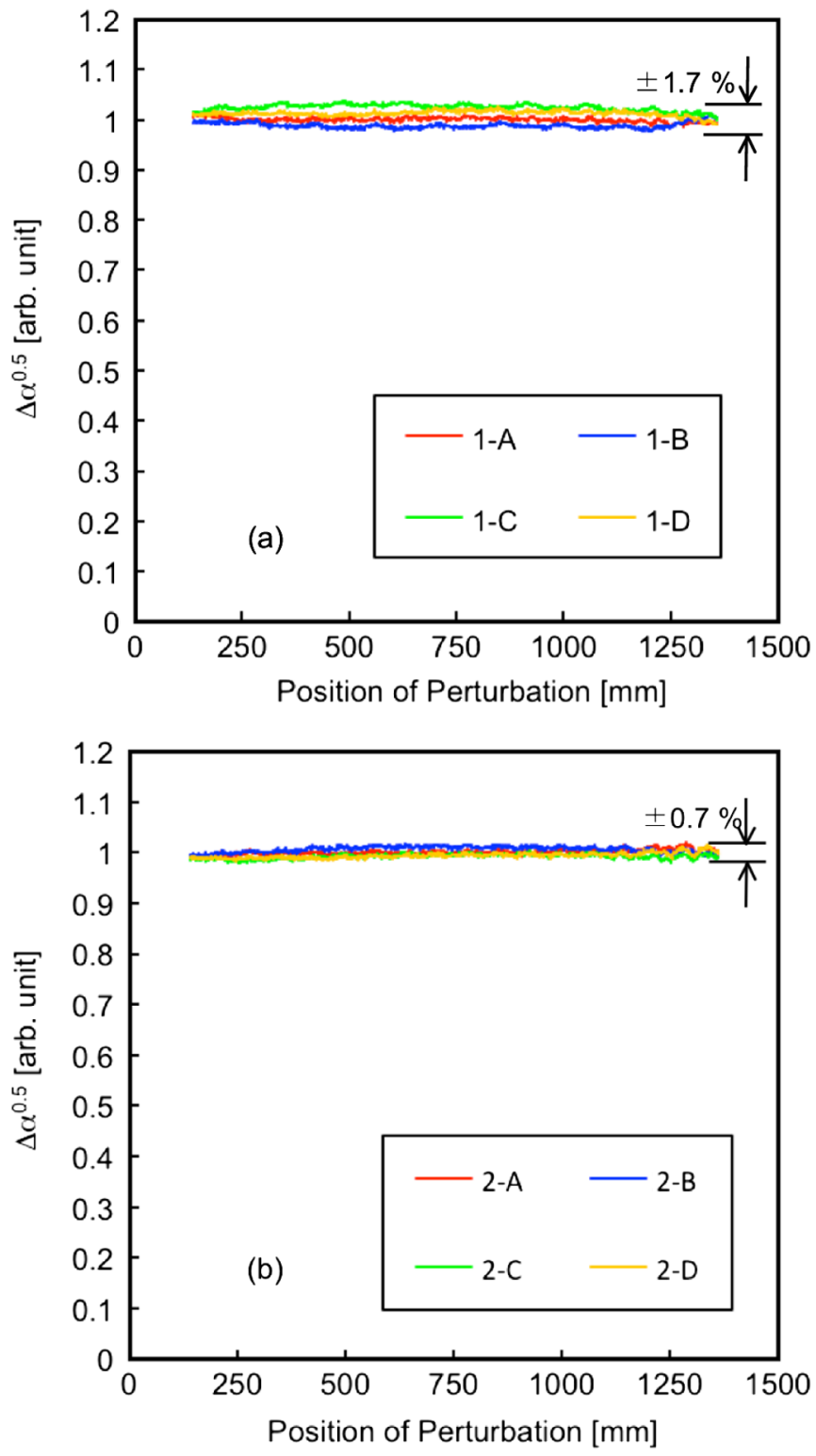

FIG. 23. Distribution plots of the electric field strength interrod along the cavity: (a) channel 1 and (b) channel 2 . 
network analyzer (Agilent Technologies, E5060B) for the measurement. As a result, the two-beam IH-RFQ cavity exhibits a resonance of approximately $47 \mathrm{MHz}$ and a $Q$ value of 5900 for the $\mathrm{TE}_{111}$ mode. This measured $Q$ value is about $80 \%$ of the calculated value in Table $\mathrm{V}$, so the wall loss would be $32 \mathrm{~kW}$ for real operating conditions. Furthermore, the wall loss is about $24 \%$ lower than the assumed power consumption, $42 \mathrm{~kW}$ based on the parameters at the basic design stage, since there is enough power to compensate.

The electric field strength in the RFQ electrode is measured by means of the bead perturbation method [5]. There is a phase difference between the incident wave to the cavity and the transparent wave from the cavity, with or without the perturbation body in the cavity. This phase difference is proportional to the electric field strength at the position of the perturbation body, and we can measure the distribution of the electric field strength along the longitudinal direction of the cavity by measuring the relative electric field strength in the cavity.

Figure 23 is a plot of the measured electric field strength. The variation of the electric field strength from the center value is $\pm 1.7 \%$ in channel 1 and $\pm 0.7 \%$ in channel 2 . As a result of the MWS simulation discussed earlier (the model is shown in Fig. 12), the alignment errors of the RFQ electrodes in each beam channel are suppressed within $\pm 50 \mu \mathrm{m}$.

\section{HIGH POWER RF TESTS}

We used a coaxial waveguide (WX-203D), with a $50 \Omega$ impedance, for the transmission of the rf power and a directional coupler for monitoring the incident and the reflection wave. A circulator, an apparatus used to remove the reflection wave influx into the rf power source, was not used, so the rf output from the power source is switched off when the reflection increases as a result of the discharge. An interlock circuit to protect the power source controls the switching of the source.

The input rf power and the interrod voltage in the cavity are measured using the pickup. Many secondary electrons are generated on a multipacting level when a high power level is input to the cavity that has not previously sustained a high power rf injection. Point discharge is also observed because the condition of the surface of the cavity is rough. As a result, the reflection rf power increases as the vacuum in the cavity degrades. Even if we can input high power rf into the cavity, discharge at the surface may cause damage to the electrodes. The input rf power to the cavity is increased gradually while monitoring closely the level of the vacuum and the intensity of discharges. As a result of this procedure, which we call "aging," we can gradually input high rf power into the cavity because the cavity surface condition is improved by small discharges. In the two-beam IH-RFQ, we aged the cavity while monitoring the temperature increase in the cooling water to avoid

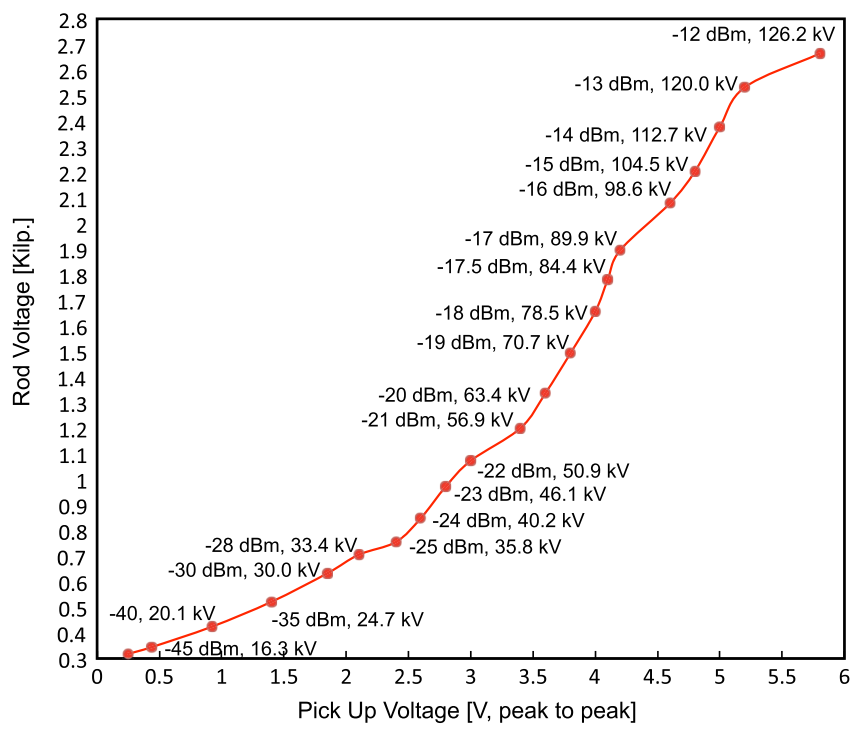

FIG. 24. A plot of the interrod voltage as a function of the pickup voltage. Decibel values refer to a signal generator (SG) output level to the rf amplifier.

temperatures of $300 \mathrm{~K}$ or higher. We also monitored the pressure in the cavity to ensure a vacuum of $10^{-3} \mathrm{~Pa}$ or less.

The aging of the cavity was performed with a duty factor of $75 \%$ until an intervane voltage of about $25 \mathrm{kV}$ was reached, $50 \%$ until the voltage reached about $33 \mathrm{kV}, 10 \%$ until the voltage reached about $79 \mathrm{kV}, 1 \%$ until the voltage reached about $105 \mathrm{kV}$, and $0.5 \%$ until the voltage reached $126 \mathrm{kV}$. The pulse rate was $100 \mathrm{~ms}$. When $20 \mathrm{kV}$ was applied to the RFQ electrodes, the interlock circuit of the rf power source was activated because of the intense discharge that occurs. The discharge did not occur after the cavity had been aged for two hours at $20 \mathrm{kV}$. The frequency of discharge was found to be small when the intervoltage exceeds $20 \mathrm{kV}$. The input rf power could be increased with ease. The input rf power and the interrod voltage were measured using the pickup antenna. We calibrated the effective area of the pickup to be about $10^{-4}$ in the voltage of the antenna compared with that of the RFQ electrode as shown in Fig. 24.

The shape of the cavity expands during aging because the cavity temperature increases as the rf input power is increased. Subsequently, the inductance of the cavity increased and the resonance frequency decreases, and we aged the cavity while tuning for the rf power source. The change in the resonance frequency is about $30 \mathrm{kHz}$ when comparing an rf power input in the interrod voltage of $85.3 \mathrm{kV}$ (Kilpatrick factor of 1.8) and no rf power input interrod.

The pulse waveforms are shown in Fig. 25 when the interrod voltage is $85.3 \mathrm{kV}$, the design value of the applied voltage to the RFQ electrode in the two-beam IH-RFQ linac, after the aging process. PG, Pf, and Pr refer to the 

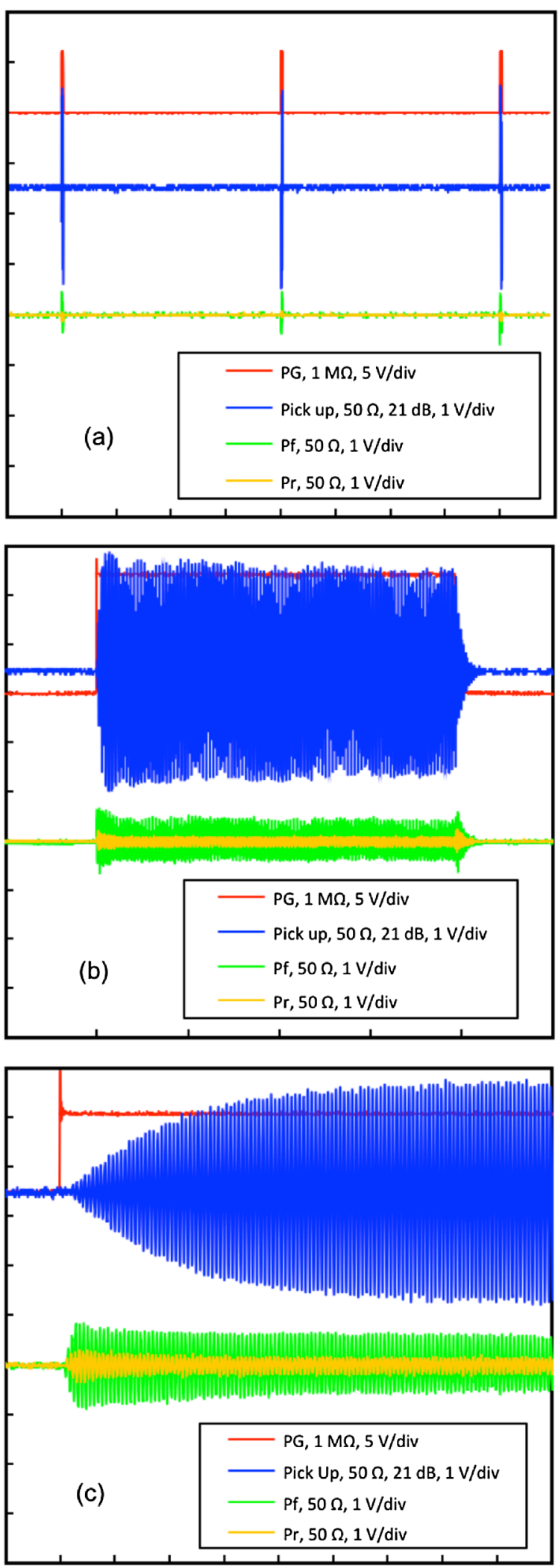

FIG. 25. Pulse waveforms in high power rf test (input frequency: $47 \mathrm{MHz}$; pulse rate: $100 \mathrm{~ms}$; pulse width: $1 \mathrm{~ms}$; duty: $1 \%$; Kilpatrick factor: 1.8). The blue colored signals labeled "Pick up" in the figure come from the monitoring antenna (pickup antenna). Time scales are (a) $25 \mathrm{~ms} / \mathrm{div}$, (b) $250 \mu \mathrm{s} / \mathrm{div}$, and (c) $50 \mu \mathrm{s} /$ div. output from a pulse generator (PG), the voltage signal of the incident wave to the cavity, and the voltage signal of the reflection wave from the cavity, respectively. The filling time of the rf is calculated to be about $126 \mu$ s using the measured $Q$ factor 5900 and the resonance frequency $47 \mathrm{MHz}$; the filling time refers to the time period during which the pulse height is at half the maximum pulse height. The calculated value is almost equal to the measured value in Fig. 25(c). The pulse width is $1 \mathrm{~ms}$ taking the filling time and the beam traveling time (dozens of microseconds) into consideration. The duty factor is $0.1 \%$ when the repetition rate of the Nd:YAG laser ion source is $1 \mathrm{~Hz}$.

\section{INJECTION SYSTEM}

We adapted and developed a laser ion source with DPIS as an injection system for the two-beam IH-RFQ linac [12]. When a solid target is irradiated with laser light, the highdensity plasma of the target is reproducibly generated. The laser ion source is an apparatus that ejects the ions as a beam from the laser ablation plasma. This injection system, using DPIS, is a high intensity heavy ion beam generator. The LEBT system between the ion source and the RFQ linac using DPIS is not needed [2], and we can increase the number of beam channels through a simple hardware structure.

A two-beam laser ion source for the two-beam IH-RFQ linac is comprised of a laser, a chamber for the plasma generation, a target, an optical system, and a vacuum system. We used a Nd:YAG laser (LUMONICS, HY400) with a $Q$ switch to generate the laser ablation plasma. The performance of this laser is shown in Table X. The cross section of the two-beam laser ion source is shown in Fig. 26. The target is a carbon plate (The Nilaco Corporation, C-073551, purity: $99.5 \%$ ). The laser light is injected into two steel pipes with flanges of VG-25. The two pipes are installed in the chamber at an angle of 30 degrees to the target surface. The entrance of the laser light in the chamber is through a BK7 window (Edmund Optics, design wave length: $1064 \mathrm{~nm}, 50 \mathrm{~mm}$ in outer diameter, $4 \mathrm{~mm}$ in thickness). The ion source chamber is sealed

TABLE X. Performance parameters of the Nd:YAG laser.

\begin{tabular}{lc}
\hline \hline Oscillation wavelength (nm) & 1064 \\
Oscillation & Pulse \\
Maximum pulse rate (Hz) & 20 \\
Pulse width at maximum output & 1.2 \\
$\quad$ energy (ns, FWHM, measured & \\
$\quad$ value in this study) & 1.2 \\
Maximum output energy & \\
$\quad(\mathrm{J} /$ shot, measured value in this study) & 6 \\
$\begin{array}{l}\text { Beam diameter at maximum output } \\
\quad \text { energy (mm) }\end{array}$ & 1.6 \\
Angle of beam spread (mrad)
\end{tabular}




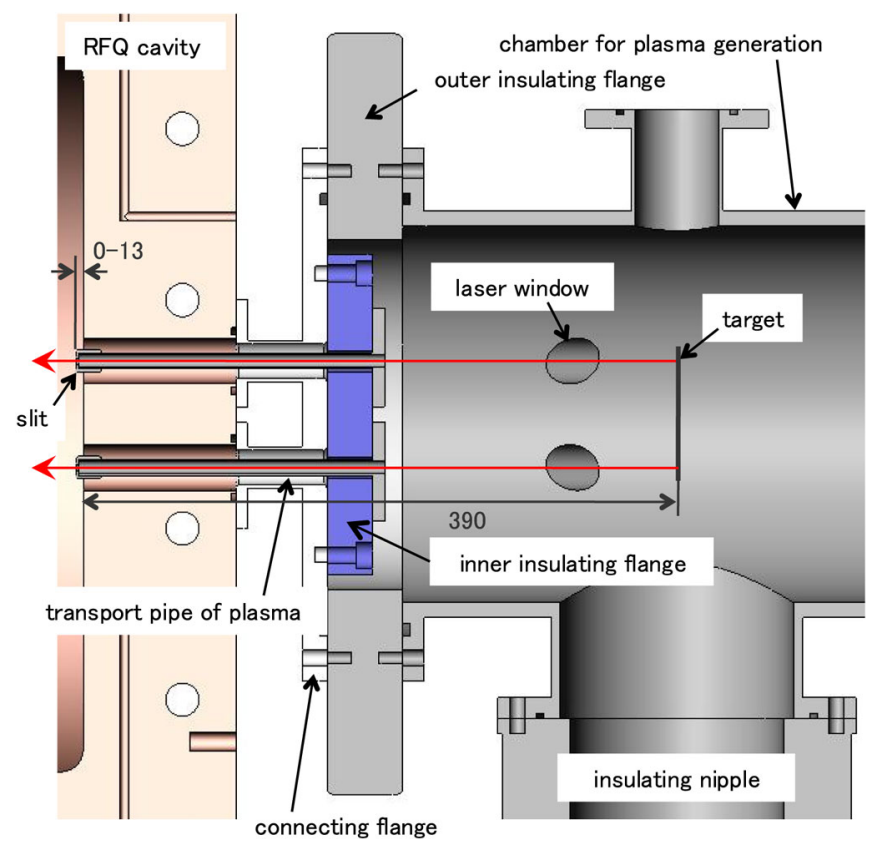

FIG. 26. Cross section of the two-beam laser ion source.

between atmosphere and the vacuum chamber by the BK7 window and an O-ring (V-34) on the surface of the window. A voltage of $30 \mathrm{kV}$ is applied to the chamber and the two plasma transport pipes in order to inject $\mathrm{C}^{2+}$ ions at an input energy of $5 \mathrm{keV} / \mathrm{u}$ into the grounded acceleration cavity. The ion source chamber and the vacuum pump are insulated from the acceleration cavity using polyacetal flanges and a ceramic cylindrical pipe, respectively. The plasma, generated on the target, travels through the plasma transport pipe at $30 \mathrm{kV}$ and emerges from a $4 \mathrm{~mm}$ inner

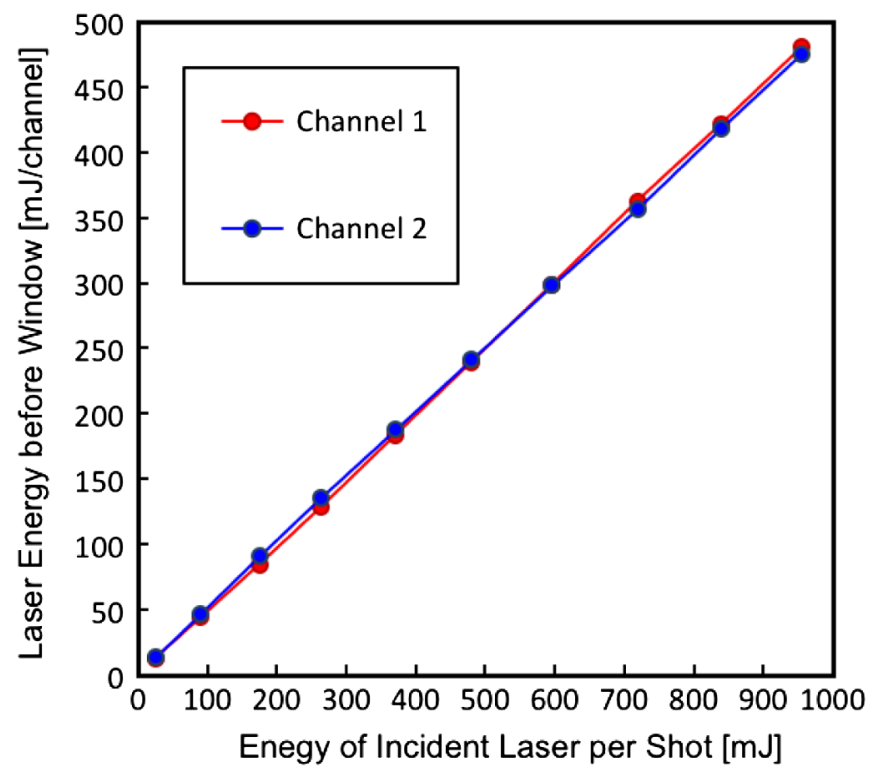

FIG. 27. Laser energy on each beam channel at entrance of the ion source chamber.
TABLE XI. Peak current and current density of each charge state in carbon ion (power density: $7.9 \times 10^{8} \mathrm{~W} / \mathrm{cm}^{2}$ ).

\begin{tabular}{lcc}
\hline \hline Charge state & $\begin{array}{c}\text { Current density } \\
\text { at the RFQ's } \\
\text { entrance }\left(\mathrm{mA} / \mathrm{cm}^{2}\right)\end{array}$ & $\begin{array}{c}\text { Peak current } \\
\text { at the RFQ's } \\
\text { entrance }(\mathrm{mA})\end{array}$ \\
\hline $\mathrm{C}^{+}$ & 151.1 & 19.0 \\
$\mathrm{C}^{2+}$ & 484.7 & 60.9 \\
$\mathrm{C}^{3+}$ & 440.4 & 55.3 \\
$\mathrm{C}^{4+}$ & 292.8 & 36.8 \\
\hline \hline
\end{tabular}

diameter pinhole on the pipe tip. A cap, with a screw thread on the inside, is installed on the pipe tip. The plasma injection position from the RFQ end plate can be adjusted from 0 to $13 \mathrm{~mm}$. The isolation flanges between the linac and the ion source were coated gradually with the generated carbon during ion source operation, providing poor electrical insulation. The flanges are therefore covered with a torus-shape barrier in order to block out the isolation flanges from the target.

The optical system, not including the BK7 window, was in atmosphere. A beam splitter (Edmund Optics, dielectric multilayer splitter with a disklike shape, design wave length: $1064 \mathrm{~nm}$, laser proof stress: $5 \mathrm{~J} / \mathrm{cm}^{2}$ ) halves the laser beam, and mirrors (Edmund Optics, design wave length: $1064 \mathrm{~nm}$, laser proof stress: $20 \mathrm{~J} / \mathrm{cm}^{2}$ ) guide the laser beams to the chamber. Planoconvex lenses (Edmund Optics, VIS-NIR multicoated), which focus the light, are $750 \mathrm{~mm}$ in focal length. Energy loss of the laser at the mirrors depends on the incidence angle to the mirrors, and fine adjustments to the mirror tilt angle were performed in order to reduce variations in the laser energy across the target surface between each beam channel. After adjustment, the laser energy of each beam channel was measured in front of the BK7 window, shown in Fig. 27. We used NOVA II made by OPHIR OPTRONICS to measure the energy. It was found that the difference in the laser energy between each beam channel is about $1 \%$.

As a result of the beam generation test, we achieved a $\mathrm{C}^{2+}$ beam with a current of about $61 \mathrm{~mA}$ at the entrance to the two-beam IH-RFQ using the laser ion source [12]. In the experiment, the distance between the target and the lens, the laser irradiated area on the target, the laser energy, and the laser power density on the target were $750 \mathrm{~mm}$, $0.042 \mathrm{~cm}^{2}, 430 \mathrm{~mJ} / \mathrm{channel}$, and $7.9 \times 10^{8} \mathrm{~W} / \mathrm{cm}^{2}$, respectively. The peak current of the carbon ions in each charge state is shown in Table XI. Carbon ions of the nondesired charge state are injected to the linac using this DPIS system.

\section{BEAM ACCELERATION TESTS}

\section{A. Test system}

We built a test system to validate the current linac design by means of combining the two-beam IH-RFQ linac and 


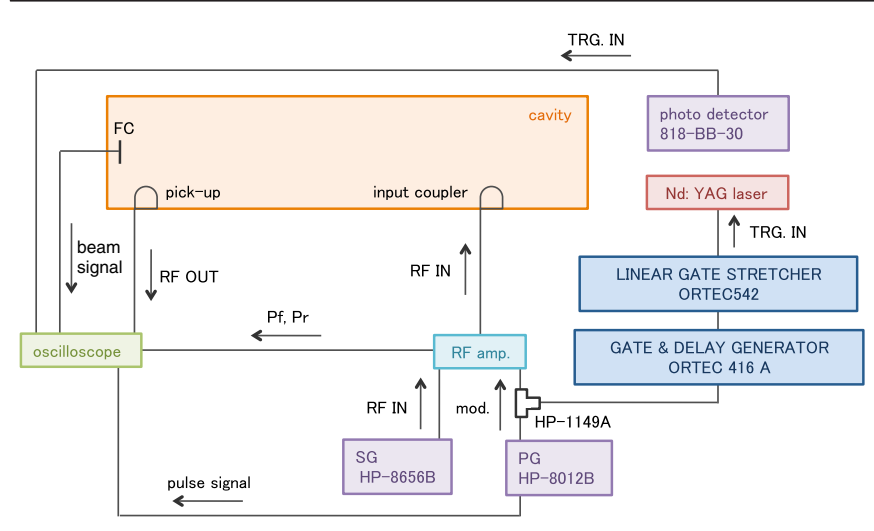

FIG. 28. Layout of the beam acceleration system. SG and PG refer to a signal generator and pulse generator, respectively.

the two-beam laser ion source with DPIS. The conditions of the tests were $1 \mathrm{~Hz}$ in the pulse repetition frequency, $1 \mathrm{~ms}$ in the pulse width, and $0.1 \%$ in the duty factor. The pressure in this system was about $8 \times 10^{-5} \mathrm{~Pa}$. Turbomolecular pumps were used as the main pumps. The exhaust velocities are $1000 \mathrm{~L} / \mathrm{s}$ (Osaka Vacuum Ltd., TC100) at the ion source, $800 \mathrm{~L} / \mathrm{s}$ (Osaka Vacuum Ltd., TG800F) at the acceleration cavity, and $500 \mathrm{~L} / \mathrm{s}$ (ULVAC, UTM-500) at the analyzer. A trigger signal to the rf power source and the laser was produced from a PG as shown in Fig. 28. In order to work the laser after the filling time of the rf, the signal from the PG to the laser was delayed using a gate and delay generator (ORTEC $416 \mathrm{~A}$ ). The pulse width of the signal that is passed through the ORTEC $416 \mathrm{~A}$ is too short, so the pulse width is increased using a linear gate stretcher (ORTEC 542) after the ORTEC 416 A.

The test apparatus used in the current measurements is shown in Fig. 29(a). Plasma from the ion source is injected to the RFQ electrode at $404.8 \mathrm{~mm}$ downstream from the target surface. A Faraday cup (FC), $26 \mathrm{~mm}$ in diameter, located at $1980 \mathrm{~mm}$ downstream from the target surface measures the beam current from the RFQ linac. When the FC is installed in the acceleration cavity, it picks up a part of the stored rf power. In this study, the FC picked up noise of several dozen volts when the interrod voltage was about $85 \mathrm{kV}$ (Kilpatrick factor of 1.8), and we set two metallic meshes between the RFQ exit and the FC. These meshes are grounded. The transmission through one mesh is about $71 \%$, and the noise in the FC is reduced to several millivolts or less. We measured the accelerated beam current using these meshes and calculated the beam current taking the transmission of these meshes into consideration. The zero point of the time axis is the time that a photon detector (New Port, InGaAs PIN detector, model 818-BB-30) registers the light from the laser.

In order to reduce secondary electron emission from the FC, we set a resistance between the FC and the oscilloscope in series and applied a self-bias voltage to the FC. The secondary emission is reduced sufficiently using a
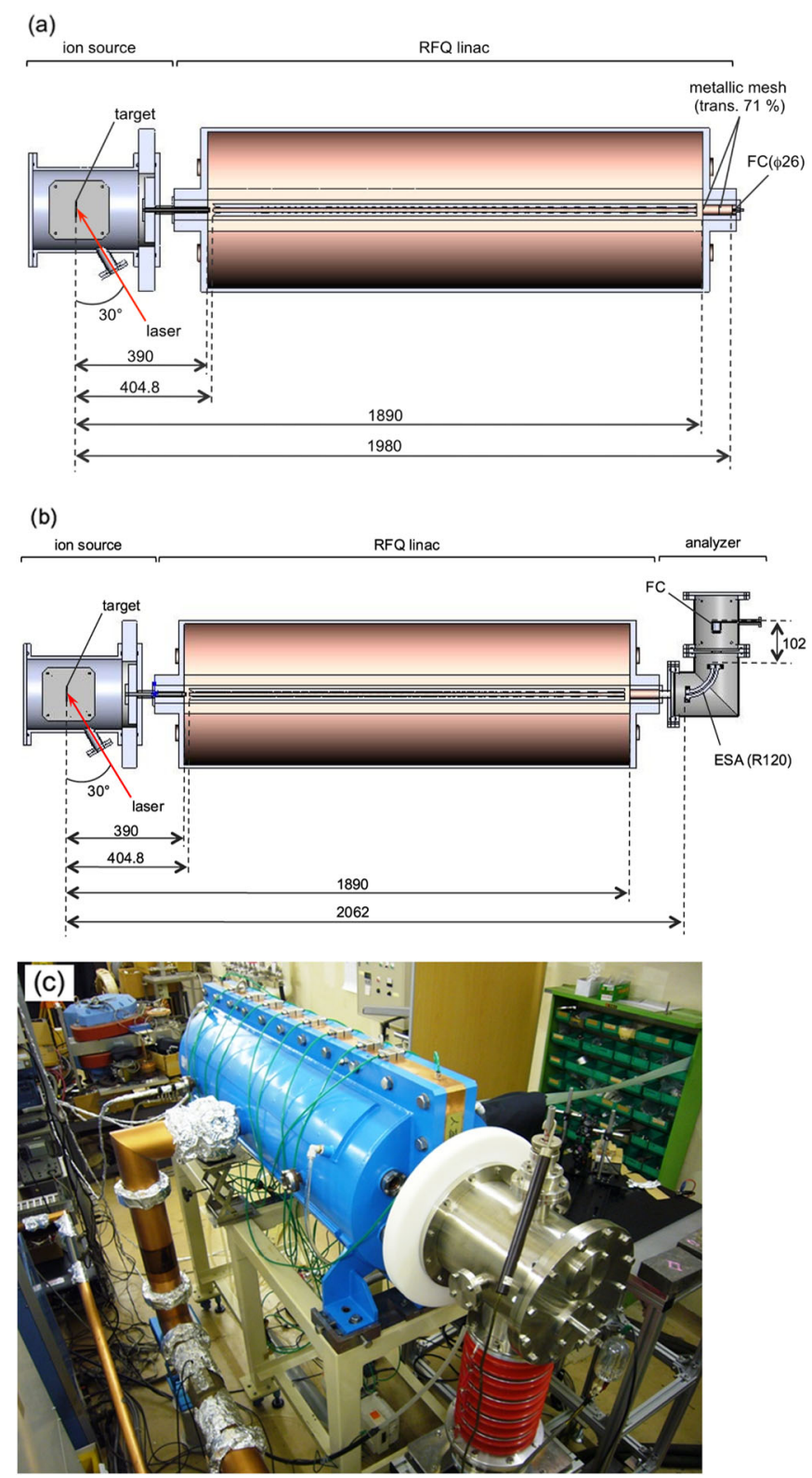

FIG. 29. Test apparatus for beam acceleration: (a) schematic drawing of a system for total output beam current measurement; (b) schematic drawing of a system to analyze the charge state of the ion beam; and (c) cover shot.

resistor of $5 \mathrm{k} \Omega$ or more, and the peak current using this resistance is about a third of that without the resistance as shown in Fig. 30. We use a resistance of $10 \mathrm{k} \Omega$ for the beam acceleration test and terminate with $50 \Omega$.

The apparatus used to analyze the charge states of the carbon ions in the accelerated beam is shown in Fig. 29(b). A deflection electrode at $2062 \mathrm{~mm}$ downstream from the target surface analyzes the charge states. A FC, $32 \mathrm{~mm}$ in diameter and located at $2352 \mathrm{~mm}$ downstream from the target surface, was used to measure the beam current. We did not use metallic meshes in this apparatus and terminated with a $10 \mathrm{M} \Omega$ resistor. 


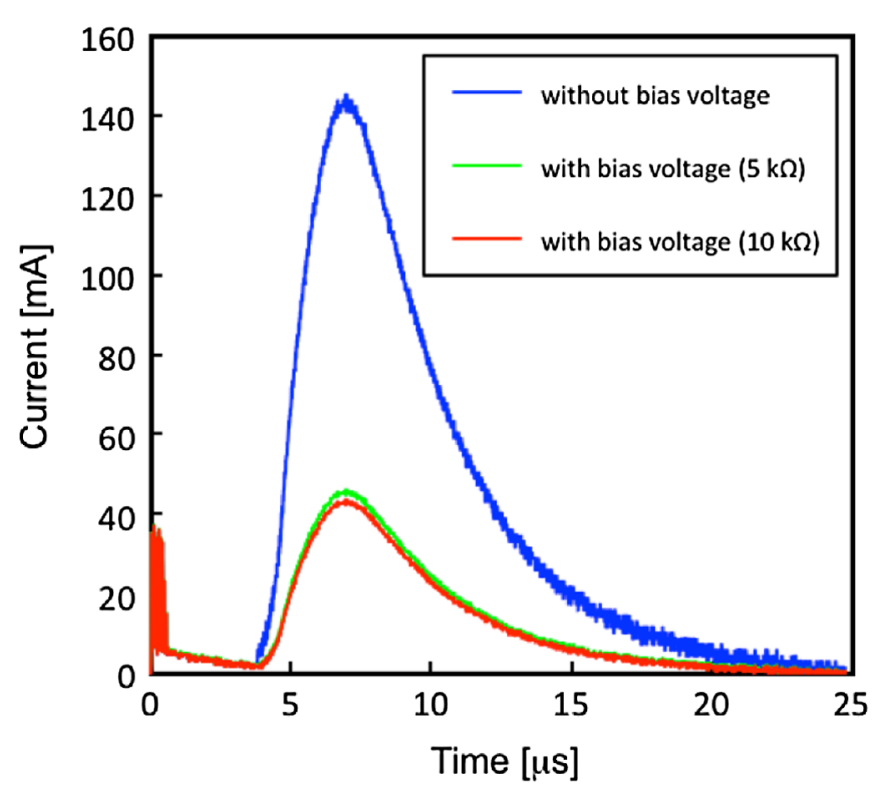

FIG. 30. Beam current waveform with self-bias (ion extraction voltage: $30 \mathrm{kV}$; pickup voltage: $5.2 \mathrm{~V}$; plasma injection point: $6 \mathrm{~mm})$.

The specifications of an electrostatic analyzer (ESA) used in the analysis are shown in Table XII. The detector for the analyzed beam can be installed at the FC or at the secondary electron multiplier and can measure the beams from each beam channel simultaneously.

\section{B. Preliminary experiment}

In order to match the generated beam from the ion source with the acceptance of the RFQ linac, we searched for the most suitable input position of the plasma to the RFQ electrode. The input surface of the plasma was adjusted by rotating the cap at the tip of the plasma transport pipe as shown in Fig. 26. The output beam current from the RFQ linac was only several dozen $\mu \mathrm{A}$ without the plasma transport pipe. The reason is that the generated plasma in the ion source with $30 \mathrm{kV}$ was accelerated to the wall of the grounded cavity, and the input current density decreased sharply.

The peak current of the accelerated beam is shown in Fig. 31. when the distance between the tip of the RFQ electrode and the input surface of the plasma is from 0 to $10 \mathrm{~mm}$. When the plasma input surface was inserted

TABLE XII. Capabilities of electrostatic analyzer.

\begin{tabular}{lc}
\hline \hline Shape of deflection electrode & Cylindrical form \\
Angle of deflection (degree) & 90 \\
Inner radius of deflection electrode $(\mathrm{mm})$ & 117 \\
Outer radius of deflection electrode $(\mathrm{mm})$ & 123 \\
Electrode interval $(\mathrm{mm})$ & 6 \\
Slit aperture width $(\mathrm{mm})$ & $0.5-3$ \\
Maximum impressed voltage $(\mathrm{kV})$ & 25 \\
\hline \hline
\end{tabular}

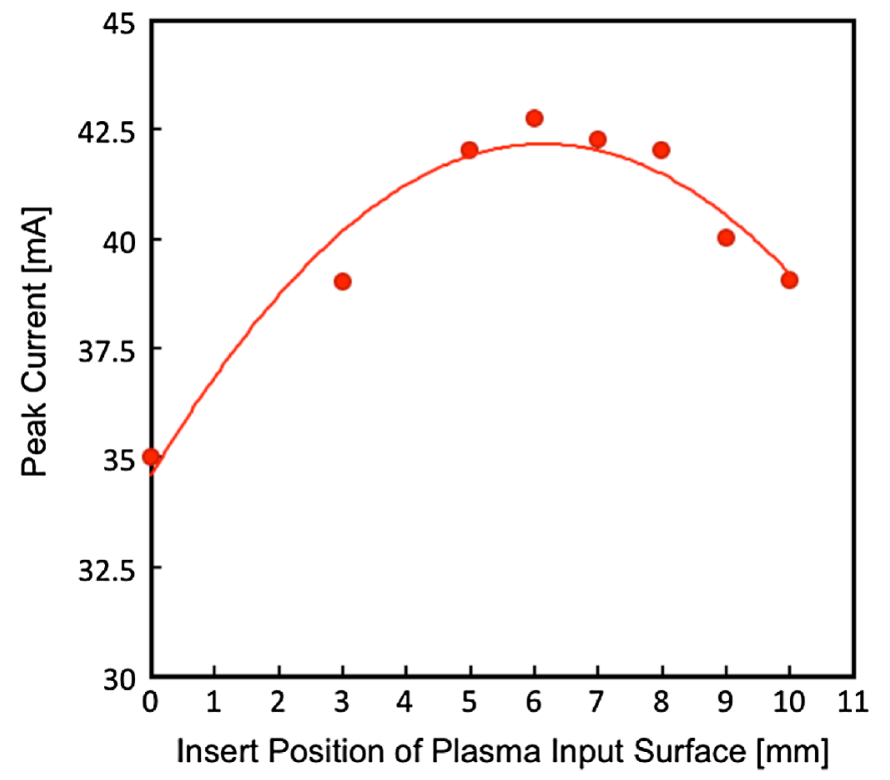

FIG. 31. Peak output current from beam channel 1 as a function of the plasma input position (pickup voltage: $5.2 \mathrm{~V}$; extraction voltage: $30 \mathrm{kV}$ ).

$11 \mathrm{~mm}$ from the RFQ's end plate, an electric discharge occurred between the tip of the RFQ electrode and the tip of the plasma transport pipe, and we could not insert the cap to the RFQ electrode. There is a suitable plasma input position for the output peak beam current, since the suitable position depends on the plasma state. The plasma in this laser irradiation configuration is more readily accepted into the RFQ linac at an input position of about $6 \mathrm{~mm}$.

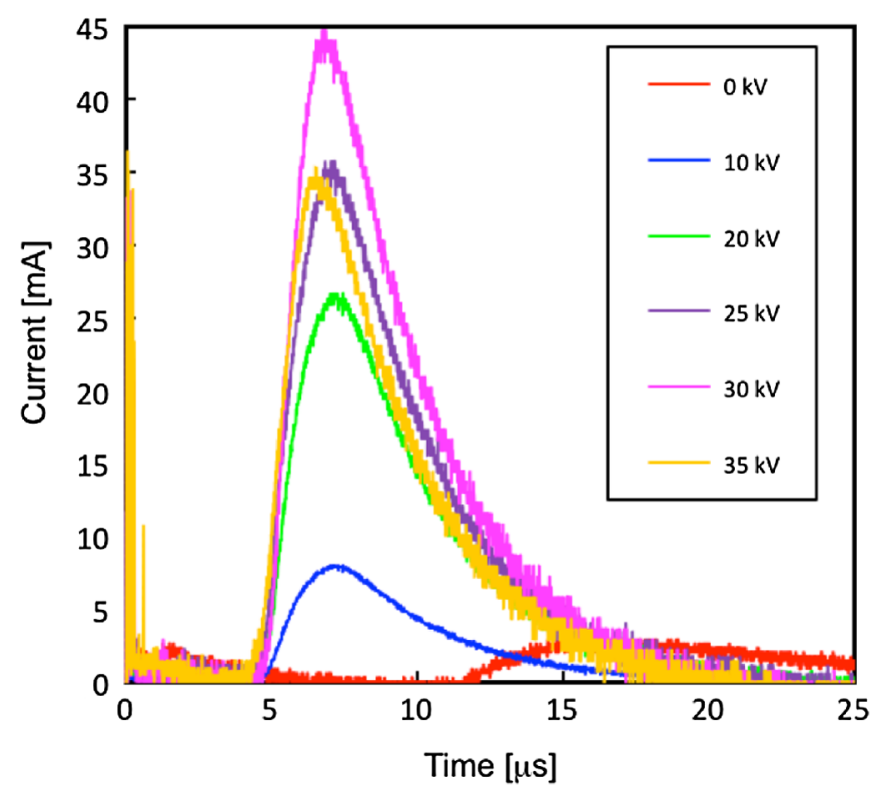

FIG. 32. Output waveform from beam channel 1 by extraction of the voltage of the plasma in the ion source (pickup voltage: $5.2 \mathrm{~V}$; plasma input position: $6 \mathrm{~mm}$ ). 
TABLE XIII. The extraction voltage for each carbon charge state for a two-beam IH-RFQ linac.

\begin{tabular}{lc}
\hline \hline Charge state & Extraction voltage $(\mathrm{kV})$ \\
\hline $\mathrm{C}^{+}$ & 60 \\
$\mathrm{C}^{2+}$ & 30 \\
$\mathrm{C}^{3+}$ & 20 \\
$\mathrm{C}^{4+}$ & 15 \\
\hline \hline
\end{tabular}

We measured the beam current with respect to the extraction voltage changing in the ion source in order to match the input energy to the input condition of the RFQ linac as shown in Fig. 32. The compatibility condition of the input energy for the two-beam IH-RFQ linac is $5 \mathrm{keV} / \mathrm{u}$, and the extraction voltage in this condition in each charge state of the carbon ion is shown in Table XIII. A sharp peak is measured at an extraction voltage of $20 \mathrm{kV}$ or greater because the accelerated particle in the linac design is $q / A=1 / 6$ or greater. The linac accelerates not only $\mathrm{C}^{2+}$ but also $\mathrm{C}^{3+}$ and $\mathrm{C}^{4+}$ at an extraction voltage of $20 \mathrm{kV}$ or greater. The reason why the peak current decreases for a further increase in the extraction voltage is that the number of the unadapted ions for the longitudinal acceptance of the RFQ linac increases. The beam commissioning was conducted with the extraction voltage $30 \mathrm{kV}$.

\section{Commissioning}

The pulse shapes in each beam channel are in agreement with each other as shown in Fig. 33. The variation of the peak current between each channel is about $0.5 \%$. The

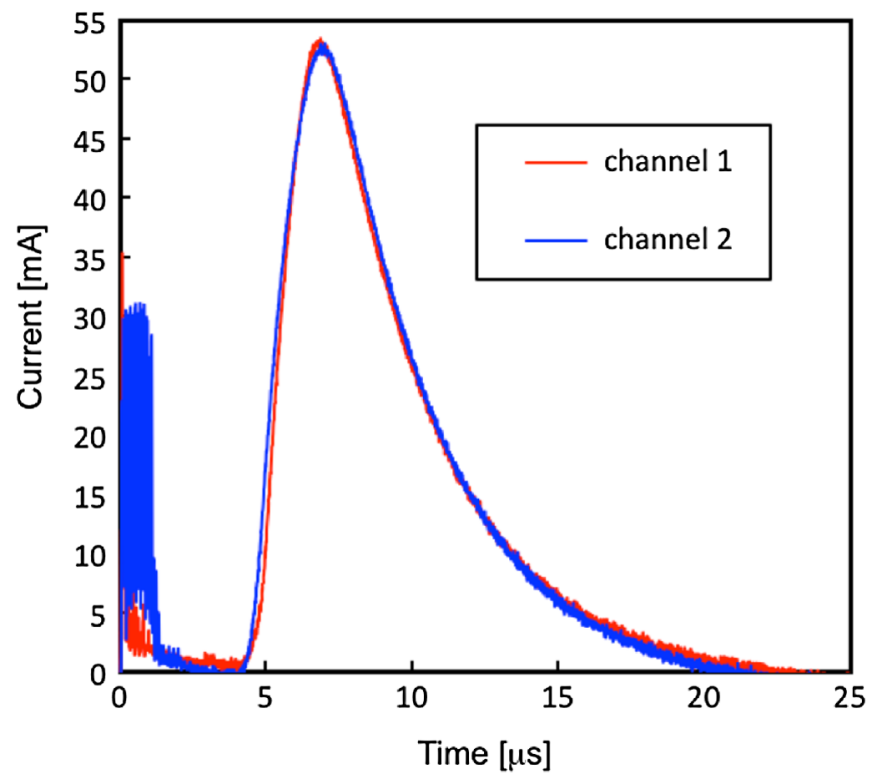

FIG. 33. Comparison of output beam current waveforms between each beam channel (pickup voltage: $6 \mathrm{~V}$; plasma input position: $6 \mathrm{~mm}$; extraction voltage: $30 \mathrm{kV}$ ). The waveform is averaged by eight laser shots. beam pulse widths are about $4.5 \mu \mathrm{s}$ in channel 1 and about $4.9 \mu \mathrm{s}$ in channel 2 . When the variability of the electric field strength in each quadrant at the rods is within a value as shown in Fig. 23, the pulse shapes of the output beams in each channel are negligibly different. The alignment error of the laser irradiation position on the target has a much greater influence on the waveform of the beam current compared with the variability of the electric field strength as we discuss later.

We measured the bunch structure of the accelerated beam on a smaller time scale. Figure 34 shows a signal around the peak current of the output beam. There is modulation in the beam signal at the same period as the rf, since this is the bunch structure of the accelerated beam. The separation between each bunch is imperfect in this measurement result. In this case, the space charge effect is still strong after the acceleration because the number of cells of the acceleration section in this RFQ linac is one. The imperfection of the bunch separation would be due to the bunch spread to longitudinal direction by the space charge effect during the traveling through a drift space from the RFQ electrode exit to the FC. The phase difference of the modulation between each beam channel is $\pi$, since the installation position of the rods at the stems is reversed between each beam channel, as shown in the lower left image of Fig. 1(b).

We specifically displaced the laser irradiation position on the target and measured the influence of the alignment

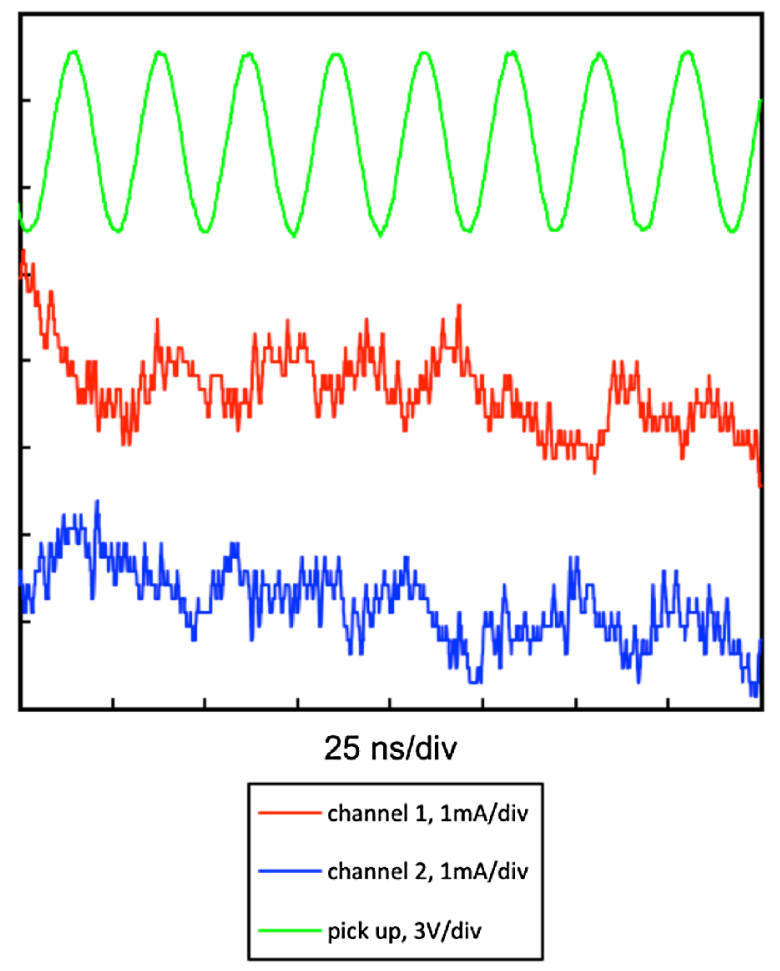

FIG. 34. Bunch structure of the acceleration beam (extraction voltage: $30 \mathrm{kV}$; plasma input position: $6 \mathrm{~mm}$ ). 


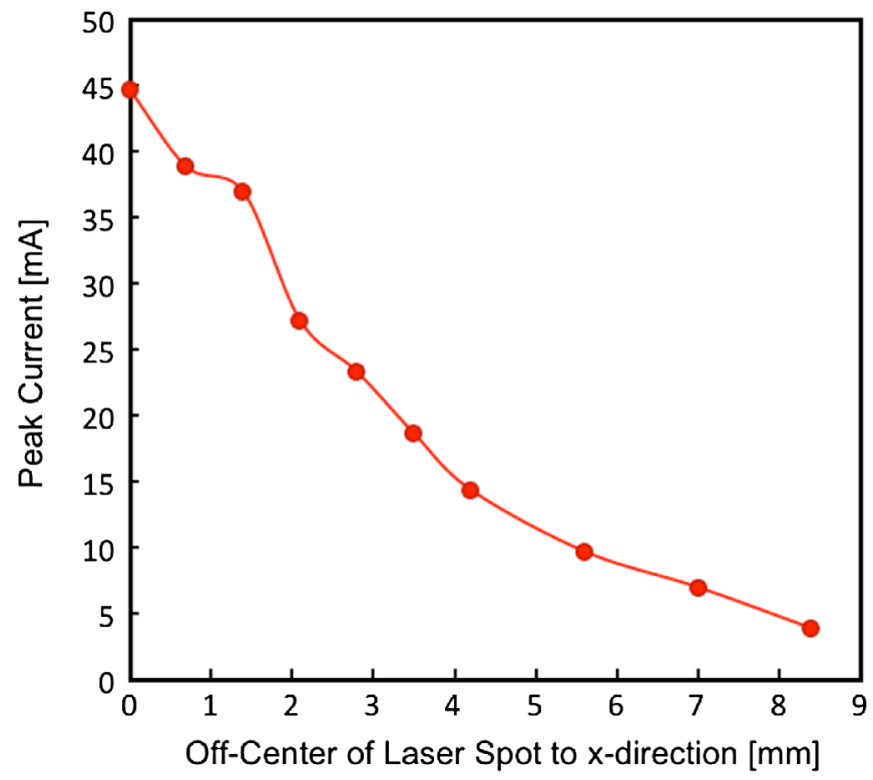

FIG. 35. Relationship between output beam current from channel 1 and laser irradiated point on the carbon target (pickup voltage: $5.2 \mathrm{~V}$; plasma input position: $6 \mathrm{~mm}$; extraction voltage: $30 \mathrm{kV})$.

error on the beam current as shown in Fig. 35. In this measurement, the zero point of horizontal axis refers to a fixed position with an accuracy of the theodolite (about $\pm 10 \mu \mathrm{m})$. When the irradiation position is displaced $500 \mu \mathrm{m}$ from the target center, the beam current decreases by about $10 \%$. This error is almost equivalent to the displacement of the mirror angle by $1 \mathrm{mrad}$, and the influence of the irradiation position on the beam current is significant.

The interrod voltage, the beam acceleration gradient, and the beam transmission level are found to increase

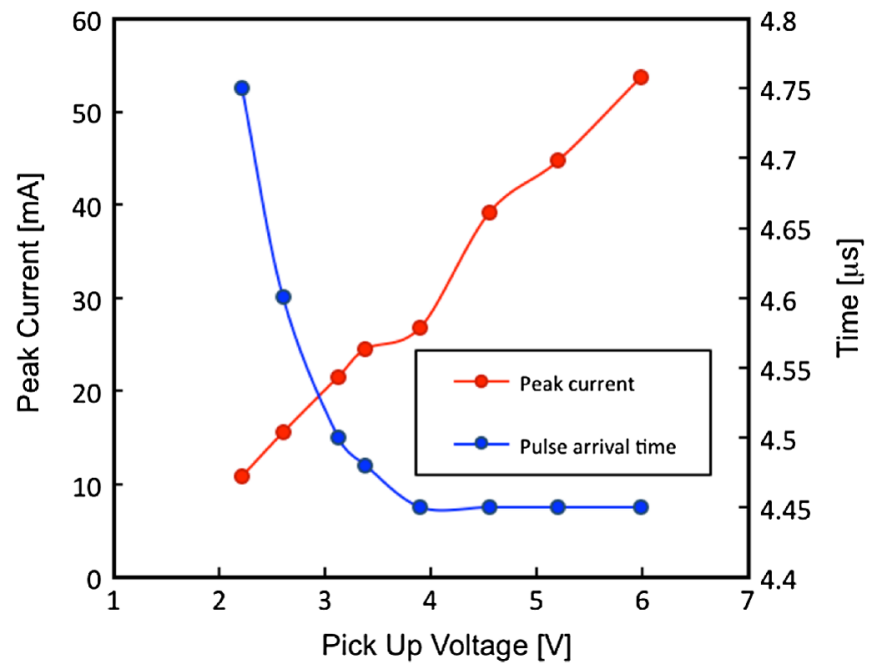

FIG. 36. Peak output current and the pulse arrival time on channel 1 as a function of the pickup voltage (plasma input position: $6 \mathrm{~mm}$; extraction voltage: $30 \mathrm{kV}$ ).
TABLE XIV. Transit condition of carbon ions in the electrostatic analyzer.

\begin{tabular}{lcc}
\hline \hline Charge state & $\begin{array}{c}\text { Analyzer } \\
\text { voltage } \\
(\mathrm{kV}, 60 \mathrm{keV} / \mathrm{u})\end{array}$ & $\begin{array}{c}\text { Analyzer } \\
\text { voltage } \\
(\mathrm{kV}, 5 \mathrm{keV} / \mathrm{u})\end{array}$ \\
\hline $\mathrm{C}^{+}$ & 36 & 3 \\
$\mathrm{C}^{2+}$ & 18 & 1.5 \\
$\mathrm{C}^{3+}$ & 12 & 1 \\
$\mathrm{C}^{4+}$ & 9 & 0.75 \\
\hline \hline
\end{tabular}

when the rf power is increased. The output beam current and the pulse arrival time at the FC and the input rf power are shown in Fig. 36. Taking note of the pulse arrival time, the arrival time is faster when the interrod voltage is increased. The pulse arrival time converges to a constant value at a pickup voltage of about $5.5 \mathrm{~V}$ (input rf power: about $70 \mathrm{~kW}$ ) or greater because the RFQ linac has an effect that over accelerated beams are decelerated. The output beam energy remains therefore about $60 \mathrm{keV} / \mathrm{u}$.

The beam transmission increases because the beam focusing is strengthened at higher input rf power. When the pickup voltage is $6 \mathrm{~V}$ (input rf power: about $75 \mathrm{~kW}$ ), the maximum beam current is about $54 \mathrm{~mA} /$ channel. The output beam current per cavity is $108 \mathrm{~mA}$. We could not measure the saturation of the beam current at a higher input power because an electric discharge occurs over the input.

We measured the accelerated beam energy in the twobeam IH-RFQ linac using the test bench for charge state analysis as shown in Fig. 29(b). Carbon ions in each charge state that transit through the ESA are shown in Table XIV.

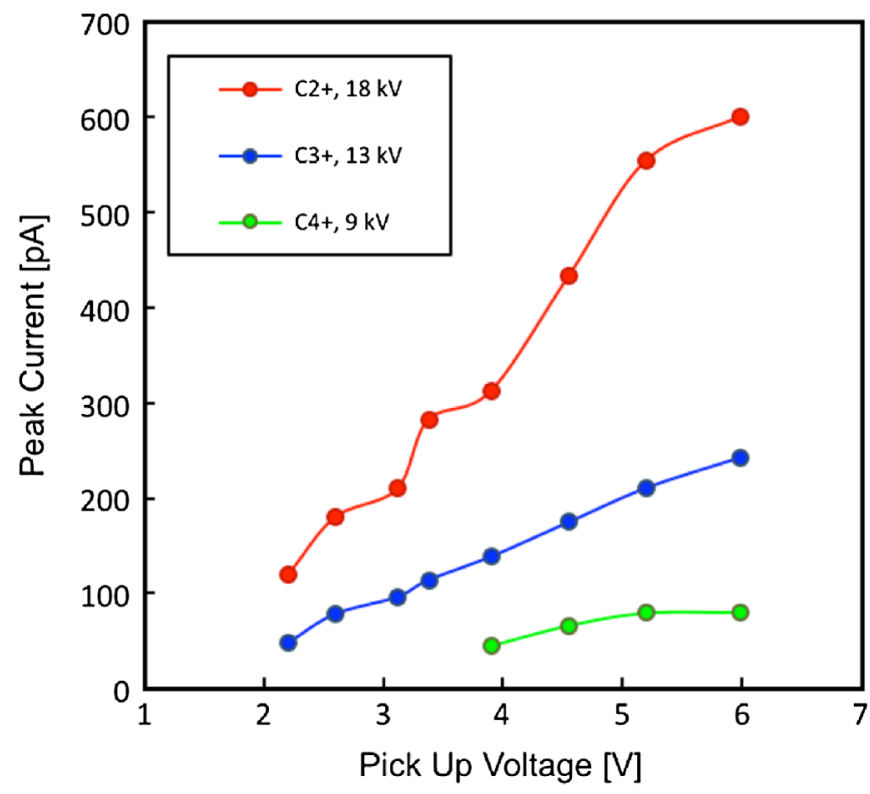

FIG. 37. Analyzed output current on channel 1 as a function of the pickup voltage (extraction voltage: $30 \mathrm{kV}$; plasma input position: $6 \mathrm{~mm}$ ). 
In this analysis, the aperture width for the slits, installed at the entrance and the exit of the analyzer, was $3 \mathrm{~mm}$. The relationship between the pickup voltage and the analyzed beam current of each charge state is shown in Fig. 37. The analyzed beam intensity of each charge state increases with higher input rf power, since this beam signal is a carbon beam of $60 \mathrm{keV} / \mathrm{u}$. As a result of this analysis, the twobeam IH-RFQ linac is found to accelerate the carbon beam from 5 to $60 \mathrm{keV} / \mathrm{u}$, as designed.

A result of the beam acceleration test in the two-beam IH-RFQ linac is summarized in Table XV. We set the shunt impedance of the two-beam IH-RFQ linac against the shunt impedances of the RFQ linacs, manufactured by other groups, as shown in Fig. 38 [10]. We can estimate the shunt impedance of a RFQ linac with a $47 \mathrm{MHz}$ operating frequency at about $332 \mathrm{k} \Omega \mathrm{m}$ from the specifications of the manufactured RFQ linacs, which use a single beam type cavity. The shunt impedance of the two-beam IH-RFQ linac is about $168 \mathrm{k} \Omega \mathrm{m}$, where this value is approximately half of the RFQ linac $(332 \mathrm{k} \Omega \mathrm{m})$. The lower impedance is due to the increase in the wall loss from the electrode elements in the cavity. This result is consistent with a simulation result in Fig. 19, and the twobeam IH-RFQ linac of this work exhibits a performance in agreement with the predefined design values.

TABLE XV. Summary of the beam acceleration test (room temperature: $19.9^{\circ} \mathrm{C}$; cooling water temperature: $19.9^{\circ} \mathrm{C}$; cavity temperature: $19.5^{\circ} \mathrm{C}$; humidity: $43 \%$; pressure: $8 \times 10^{-5} \mathrm{~Pa}$ ).

\begin{tabular}{|c|c|c|}
\hline Acceleration particle & carbon & \\
\hline rf pulse rate $(\mathrm{Hz})$ & 1 & \\
\hline rf pulse width (ms) & 1 & \\
\hline duty $(\%)$ & 0.1 & \\
\hline Resonance frequency (MHz) & 47.0 & \\
\hline$Q$ factor & 5900 & \\
\hline$R / Q(\mathrm{k} \Omega \mathrm{m})$ & 168 & \\
\hline Laser energy (mJ/channel) & 430 & \\
\hline Laser pulse width (ns, FWHM) & 13 & \\
\hline Irradiation area $\left(\mathrm{cm}^{2}\right)$ & 0.042 & \\
\hline Power density $\left(\mathrm{W} / \mathrm{cm}^{2}\right)$ & $7.9 \times 10^{8}$ & \\
\hline Input energy $(\mathrm{keV} / \mathrm{u})$ & 5 & \\
\hline Input current (mA/channel, total) & 172 & \\
\hline$\left(\mathrm{mA} /\right.$ channel, $\left.\mathrm{C}^{2+}\right)$ & 61 & \\
\hline$\left(\mathrm{mA} /\right.$ channel, $\left.\mathrm{C}^{3+}\right)$ & 55 & \\
\hline$\left(\mathrm{mA} /\right.$ channel, $\left.\mathrm{C}^{4+}\right)$ & 37 & \\
\hline Output energy $(\mathrm{keV} / \mathrm{u})$ & 60 & \\
\hline Output current (mA/channel, total) & 45 & 54 \\
\hline$\left(\mathrm{mA} /\right.$ channel, $\left.\mathrm{C}^{2+}\right)$ & 30 & 36 \\
\hline$\left(\mathrm{mA} /\right.$ channel, $\left.\mathrm{C}^{3+}\right)$ & 12 & 15 \\
\hline$\left(\mathrm{mA} /\right.$ channel, $\left.\mathrm{C}^{4+}\right)$ & 3 & 3 \\
\hline Input rf power $(\mathrm{kW})$ & 65 & 76 \\
\hline Pickup voltage $(\mathrm{V}, 50 \Omega)$ & 5 & 6 \\
\hline Kilpatrick factor (without beam loading) & 2.5 & 2.7 \\
\hline
\end{tabular}

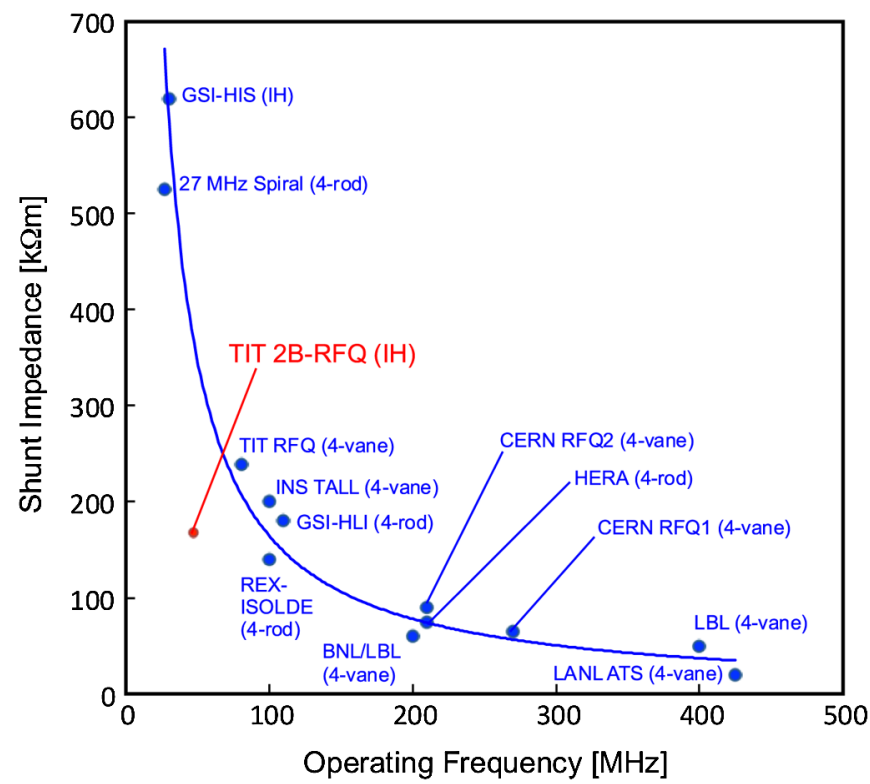

FIG. 38. Major RFQ linacs in operation globally and their corresponding shunt impedances.

\section{Beam loading property}

In order to evaluate the multibeam loading, we accelerated the beam using channel 2 only and blocked the laser beam path of channel 1 . The peak beam current as a function of pickup current is shown in Fig. 39. Comparing the two-beam and single beam loading at the same input power, the beam current of the latter is greater over the 1 to $6.5 \mathrm{~V}$ pickup voltage range. The excess $\mathrm{rf}$ power, used for the two-beam acceleration, is used to apply

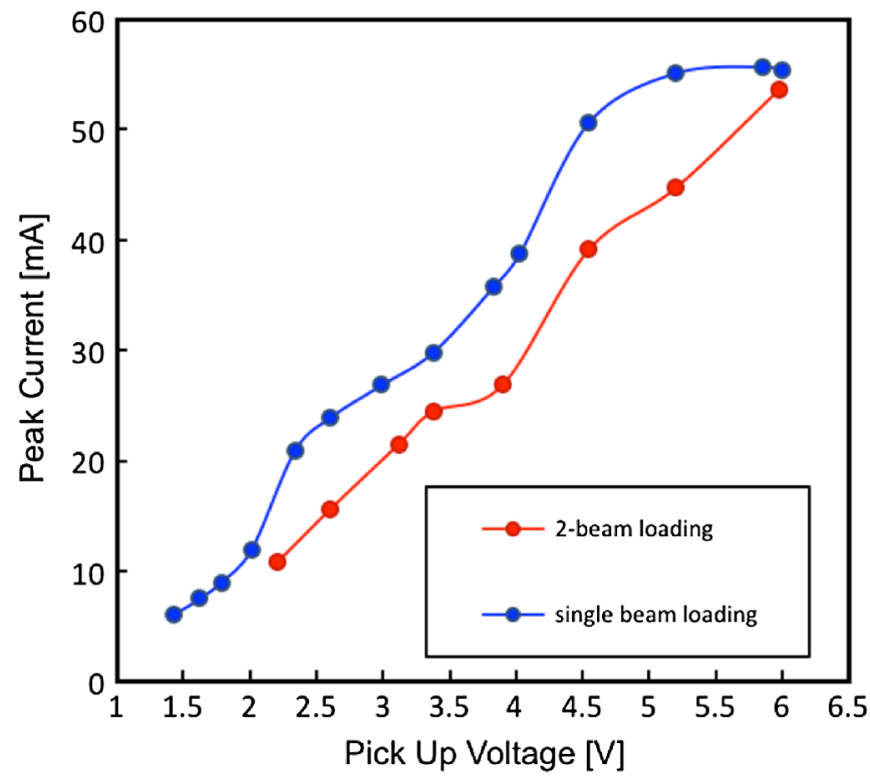

FIG. 39. Peak output current from channel 2 in single and twobeam loading (plasma input position: $6 \mathrm{~mm}$; extraction voltage: $30 \mathrm{kV}$ ). 


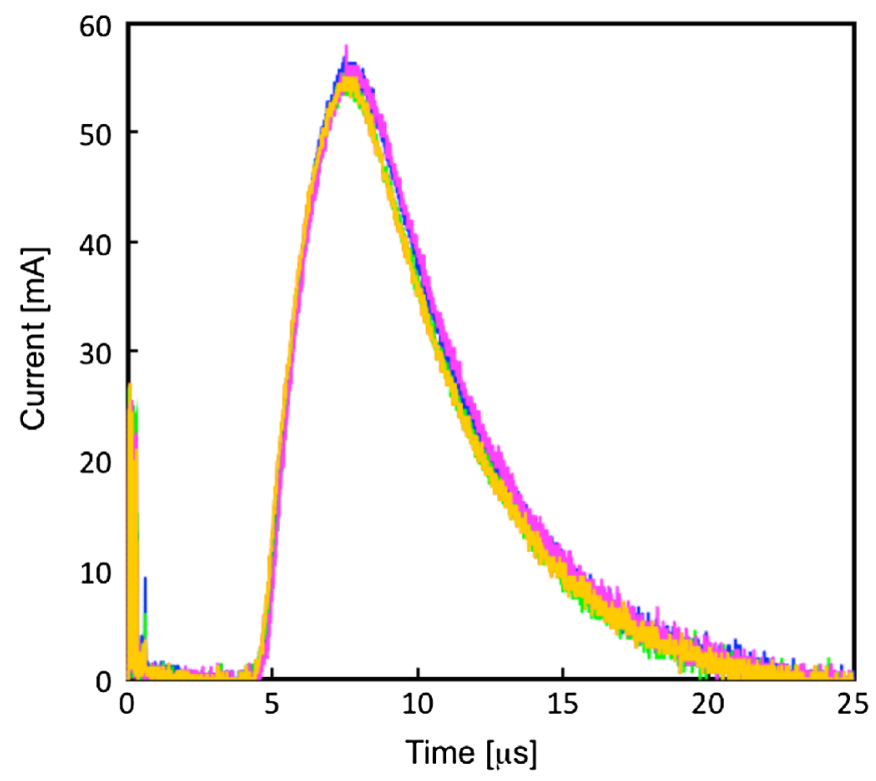

FIG. 40. Beam current waveform from channel 2 in single beam loading (pickup voltage: $5.2 \mathrm{~V}$; plasma input position: $6 \mathrm{~mm}$; extraction voltage: $30 \mathrm{kV}$ ). This graph is a superposition of the output beams in five laser shots.

the interrod voltage in the single beam loading, so the beam transmission increases compared to the two-beam loading. We can also measure the saturation of the output beam current at a higher input power in the single beam loading, and the value is about $55.6 \mathrm{~mA}$. If more rf power can be input to the cavity in two-beam loading, the output current would converge to approximately $55.6 \mathrm{~mA}$.

The pulse waveform of the output beam in single beam loading is shown in Fig. 40. The variability of the peak current in the five shots overlay is within $5 \%$, the beam is reproducible and accelerated in the single beam loading as well as in the two-beam loading case.

We measured the output current from channel 2 when the input current to channel 1 is changed by means of displacing the laser irradiation position on the target as shown in Fig. 41. In this case, the input current to channel 2 is fixed. We expected that the output beam current from channel 2 would increase when the input current to channel 1 decreases because the excess power, used for beam acceleration on channel 1, would be used for beam acceleration on channel 2. However, the output beam current on channel 2 decreases until the beam current on channel 1 is about $25 \mathrm{~mA}$. The beam current on channel 2 also decreases by $10 \%$ when the beam current on channel 1 decreases by $10 \%(4 \mathrm{~mA})$. When the beam current on channel 1 decreases further, the beam current on channel 2 increases slowly, and the beam waveform on channel 2 is found to be the same as that shown in Fig. 40.

The current waveform on channel 2 is shown in Fig. 42 when the output current on channel 1 is fixed at about $25 \mathrm{~mA}$. The variability of the output beam between each

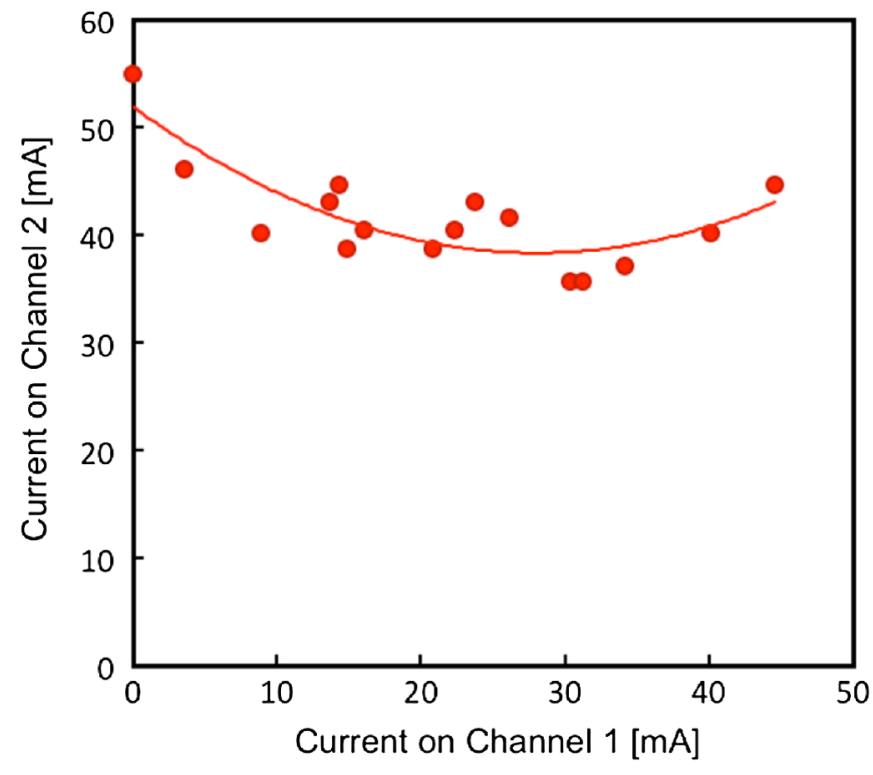

FIG. 41. Output current from channel 1 to output current from channel 2 (pickup voltage: $5.2 \mathrm{~V}$; plasma input position: $6 \mathrm{~mm}$; extraction voltage: $30 \mathrm{kV}$ ). The input current to channel 2 is fixed.

channel is about $23 \%$ in the five shot overlay, and the reproducibility of the acceleration is poor. This could be due to the coherency between the two beams derived from the imbalance of the beam loading. The coherency has little effect on the stability of the beam acceleration

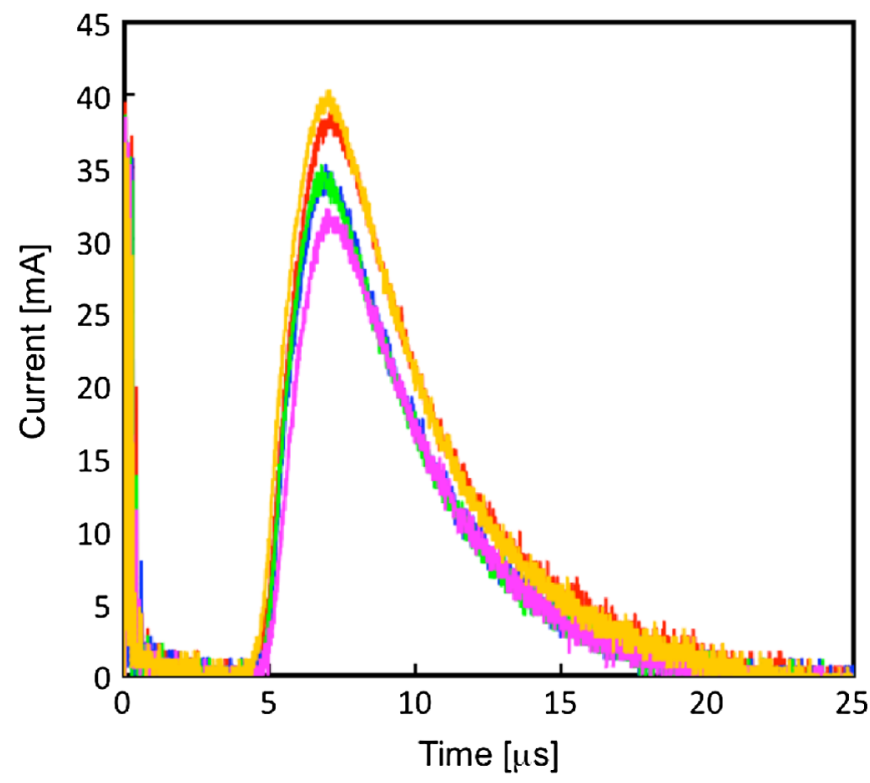

FIG. 42. Beam current waveform from channel 2 when the output current from channel 1 is fixed to $25 \mathrm{~mA}$ (pickup voltage: $5.2 \mathrm{~V}$; plasma input position: $6 \mathrm{~mm}$; extraction voltage: $30 \mathrm{kV}$ ). This graph is a superposition of the output beams in five laser shots. 
when the difference of the peak current between each channel is less than $0.5 \%$.

\section{CONCLUSIONS}

A multibeam IH-RFQ linac as a high intensity heavy ion acceleration device in the low energy region has been proposed to accelerate several beams through a single cavity, with a lower space charge effect. In this study, we manufactured a two-beam IH-RFQ linac as a prototype of the multibeam IH-RFQ linac; the IH-RFQ linac was successfully tested using carbon ions. Further, we developed a laser ion source with DPIS as an injection system for the two-beam IH-RFQ linac.

We established an engineering process for the design and the manufacture of the acceleration cavity. One RFQ acceleration cavity generates a beam current greater than $100 \mathrm{~mA}$, a difficult current level to reach using conventional methods. The peak output beam current per cavity is about $108 \mathrm{~mA}$. The beam current is higher than previously reported for heavy ion beam acceleration using a single RFQ cavity. The number of the beam channel in the RFQ linac can further increase, so a multibeam acceleration can be an effective and practical method to generate high intensity heavy ions exceeding $100 \mathrm{~mA}$ in beam current. A coherency in the two beams between each channel was observed, possibly due to an imbalance in the beam loading in the cavity. However, this is only a suggestion. In order to produce stable beams from the multibeam IH-RFQ linac further work, it would be necessary to determine the cause of the coherency.

The properties of the multibeam IH-RFQ linac compared with the other existing RFQ structures were quantitatively estimated by means of a numerical simulation. As a result of the simulations, the IH-type acceleration cavity was found to be the most power-efficient structure in the low frequency region, several dozen megahertz for heavy ion accelerations. When the heavy ion beam is several $\mathrm{keV} / \mathrm{u}$ to dozens of $\mathrm{keV} / \mathrm{u}$ in energy at a current of $20 \mathrm{~mA}$, the two-beam IH-RFQ linac has a strong advantage over the other structures because of the greater beam transmission level and power efficiency.

During this study, certain issues were identified. An existing rf power source was used for the test of the linac, and the maximum output power from the rf source limited the performance of the acceleration cavity. When the linac design includes higher input energies, the performance of the RFQ linac system is found to be greater in terms of the ion extraction from the ion source and the beam transmission of the linac. However, the unit cell of the modulation on the RFQ electrode and the cavity lengthen when the initial velocity of the accelerated particles is faster at higher input energies. The input energy of the two-beam IH-RFQ linac was set to $5 \mathrm{keV} / \mathrm{u}$ taking the cavity length limitation into consideration. If we can use a rf power source with a higher output power, the acceleration cavity could lengthen and would generate higher intensity and higher energy heavy ions.

The RFQ linac accelerates undesirable valences of ions as well as desirable valences of ions when the laser ion source with DPIS is used for the injection system. The PARMTEQM package cannot be used to calculate the beam dynamics containing a multicharge. The "real" response of the beam with multicharges is different from the results obtained from the PARMTEQM calculation, so it is necessary to study the beam dynamics using a beam dynamics simulation code such as PTEQ-HI, which can be used to incorporate multicharge effects. We also need to develop a cell parameter generation code of the RFQ electrode for multicharge ion acceleration in order to optimize the cell parameter in the acceleration.

It was shown that the input current density from the ion source to the RFQ electrode increases through experiments, when a solenoid coil was installed in the plasma transport region between the target in the ion source and the entrance of the RFQ electrode [13]. There is also the possibility that a higher intensity beam could be generated using the injection system.

The two parallel beams generated from each channel are at some distance from each other. It is necessary to merge these beams in order to use the beam for applications. This stage, called beam funneling, has been used in heavy ion inertia fusion reactors [14-16] and in fusion material irradiation facilities [17]. It is possible that the high intensity beam from the RFQ linac could be lost in a funneling stage, so it would be necessary to develop a new funneling technology that can deliver a high beam transmission level. It would also mean that the multibeam RFQ linac system could be used as the first stage linac in a heavy ion inertia fusion plant, resulting in a smaller linac system in the fusion driver. The basic research behind the heavy ion inertia fusion plant has not advanced because of the large size of the first stage linac of the current configurations. The multibeam IH-RFQ linac system using the laser ion source with DPIS would provide new developments for such a fusion plant.

[1] T. P. Wangler, Los Alamos National Laboratory Technical Report No. LA-8338, 1980.

[2] Masahiro Okamura, Hirotsugu Kashiwagi, Kazuhiko Sakakibara, Junpei Takano, Toshiyuki Hattori, Noriyosu Hayashizaki, Robert A. Jameson, and Kazuo Yamamoto, Rev. Sci. Instrum. 77, 03 B303 (2006).

[3] A. Schempp, Nucl. Instrum. Methods Phys. Res., Sect. A 415, 209 (1998).

[4] A. Firjahn-Andersch, J. Madlung, A. Shempp, and H. Zimmermann, Nucl. Instrum. Methods Phys. Res., Sect. A 415, 397 (1998).

[5] U. Ratzinger, Nucl. Instrum. Methods Phys. Res., Sect. A 464, 636 (2001). 
[6] U. Ratzinger, K. Kaspar, E. Malwitz, S. Minaev, and R. Tiede, Nucl. Instrum. Methods Phys. Res., Sect. A 415, 281 (1998).

[7] W. D. Kilpatrick, Rev. Sci. Instrum. 28, 824 (1957).

[8] Takuya Ishibashi, Noriyosu Hayashizaki, and Toshiyuki Hattori, Nucl. Instrum. Methods Phys. Res., Sect. A 606, 116 (2009).

[9] K. R. Crandall, T. P. Wangler, L. M. Young, J. H. Billen, G. H. Neuschaefer, and D. L. Schrage, Report No. LA-UR96-1836, 2005.

[10] Thomas Sieber, Dissertation der Fakultät für Physik, Ludwig-Maximilians-Universität München, 2001.

[11] H. Podlech, U. Ratzinger, D. Gorelov, W. Hartung, F. Marti, X. Wu, and R. C. York, in Proceedings of the 8th European Particle Accelerator Conference, Paris, 2002 (EPS-IGA and CERN, Geneva, 2002), p. 942.

[12] T. Ishibashi, N. Hayashizaki, J. Tamura, K. Oka, Y. Shimaya, T. Hattori, and H. Kashiwagi, Rev. Sci. Instrum. 81, 02A502 (2010).

[13] M. Okamura, A. Adeyemi, T. Kanesue, J. Tamura, K. Kondo, and R. Dabrowski, Rev. Sci. Instrum. 81, 02A510 (2010).
[14] Y. Fujii-e, S. Hayakawa, T. Hattori, H. Hirabayashi, Y. Hirao, S. Ido, A. Itano, Y. Itoh, S. Kadota, T. Katayama, H. Katsuta, S. Kawata, M. Kondo, K. Miyazaki, A. Mizobuchi, T. Murakami, S. Nakai, N. Nakamura, H. Nakashima, K. Nishihara, K. Niu, A. Noda, Y. Nomura, H. Obayashi, Y. Ohsawa, T. Suzuki, M. Takanaka, H. Tawara, N. Tokuda, N. Ueda, S. Watanabe, S. Yamada, and T. Yamaki, Plasma Physics Nagoya University Report No. IPPJ-663, 1984.

[15] B. Badger, K. Beckert, R. Bock, D. Böhne, I. Bozsik, J. Brezina, M. Corradini, L. El-Guebaly, R. Engelstad, R. Fröhlich, B. Goel, D. Henderson, W. Höbel, I. Hofmann, A. Jahnke, R. Keller, G. Kessler, A. Klein, R. Kreutz, G. Kulcinski, E. Larsen, E. Lessmann, E. Lovell, U. von Möllendorff, N. Moritz, G. Moses, R. Müller, H. Nestle, R. Peterson, K. Plute, L. Pong, H. Runge, M. Sawan, K. Schretzmann, I. Sviatoslavsky, K. Symon, D. Sze, N. Tahir, W. Vogelsang, W. Wendel, A. White, and H. Wollnik, Kahlstruhe, Germany, Reports No. KfK-3840 and No. UWFDM-625, 1984.

[16] I. Hofmann, Nucl. Instrum. Methods Phys. Res., Sect. A 415, 11 (1998).

[17] A. Mosnier and U. Ratzinger, Fusion Eng. Des. 83, 1001 (2008). 